MICHEL KURDOGLIAN LUTAIF

\title{
AUTONOMIA, INTEGRIDADE E GESTÃO UNIVERSITÁRIA NA UNIVERSIDADE DE SÃO PAULO
}

Dissertação de Mestrado

Orientadora: Professora Associada Nina Beatriz Stocco Ranieri

UNIVERSIDADE DE SÃO PAULO

FACULDADE DE DIREITO

SÃO PAULO - SP 



\title{
AUTONOMIA, INTEGRIDADE E GESTÃO UNIVERSITÁRIA NA UNIVERSIDADE DE SÃO PAULO
}

\begin{abstract}
Dissertação de Mestrado apresentada à Banca Examinadora do Programa de Pós-Graduação em Direito da Faculdade de Direito da Universidade de São Paulo, na área de concentração de Direito do Estado, sob orientação da Professora Associada Nina Beatriz Stocco Ranieri.
\end{abstract}

\section{UNIVERSIDADE DE SÃO PAULO}

FACULDADE DE DIREITO

SÃO PAULO - SP 


\section{Catalogação da Publicação \\ Serviço de Biblioteca e Documentação \\ Faculdade de Direito da Universidade de São Paulo}

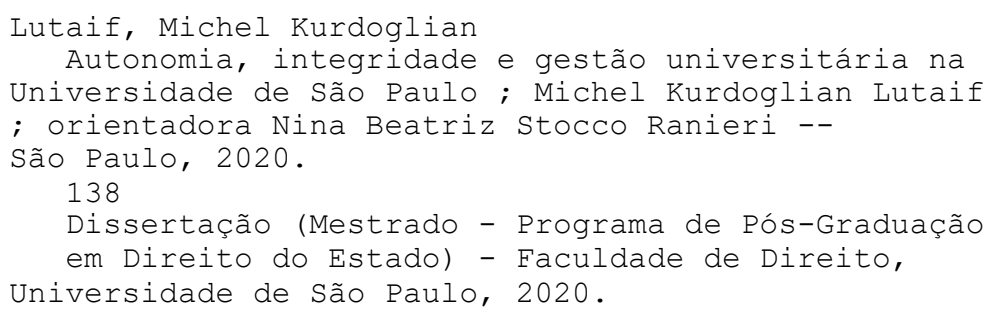

1. Autonomia universitária. 2. Integridade. 3. Gestão universitária. 4. Universidade. 5. Ensino superior. I. Ranieri, Nina Beatriz Stocco, orient.

II. Título. 
Nome: LUTAIF, Michel Kurdoglian

Título: Autonomia, integridade e gestão universitária na Universidade de São Paulo

Dissertação de Mestrado apresentada ao Programa de Pós-Graduação em Direito da Faculdade de Direito da Universidade de São Paulo para obtenção do título de Mestre em Direito - Área de Concentração: Direito do Estado.

Aprovado em:

\section{Banca Examinadora}

$\operatorname{Prof}(\mathbf{a}) . \operatorname{Dr}(\mathbf{a})$. Instituição:

Julgamento: Assinatura:

$\operatorname{Prof}(\mathbf{a}) . \operatorname{Dr}(\mathbf{a})$. Instituição:

Julgamento: Assinatura:

$\operatorname{Prof(a).} \operatorname{Dr}(a)$. Instituição:

Julgamento: Assinatura: 

Às universidades brasileiras, para que continuem sendo instituições que transformem o país. 



\section{AGRADECIMENTOS}

Tantos nomes, tantas pessoas que vem e que vão... Já manifestei em outras oportunidades que agradeço mesmo a quem não me lembro. Acredito que todos os que de algum modo passam em nossas vidas deixam a sua contribuição, e agora não é diferente. Pedindo desde já desculpas pela extensão deste tópico, seguem aqui algumas das pessoas que minha memória me permitiu lembrar.

Inicio agradecendo aos meus pais e à minha irmã, sem os quais nada seria possível.

Agradeço também à minha orientadora, Professora NINA RANIERI, por todas as oportunidades e incentivo acadêmico dados desde as aulas de Teoria do Estado, no primeiro ano da graduação, até hoje. De lá para cá, foram muitas outras aulas, monitorias, pesquisas, artigos, eventos, seminários, atividades de extensão, reuniões de grupos de estudos e tudo o mais. Devo quase todo o interesse pelo Direito Público em geral à professora, que aceitou me orientar em todos os trabalhos e atividades que propus. Nesta dissertação, suas contribuições e experiências na gestão da Universidade de São Paulo foram um grande diferencial.

Não poderia deixar de mencionar também os professores que no decorrer da pesquisa aceitaram abrir espaço em suas apertadas agendas para conversar com esse aluno de Mestrado sobre temas ousados: integridade e gestão universitária.

Assim, agradeço aos professores que me receberam: VAHAN AgOPYAN, na Reitoria da Universidade de São Paulo, pela preciosa visão que me proporcionou da gestão universitária e troca de ideias sobre os modelos de integridade; JACQUES MARCOVITCH, na FEA-USP, por logo no início ter sido grande incentivador da pesquisa, auxiliando-me com seu delineamento e diretrizes, como estudioso das universidades que é; José Goldemberg, no IEE-USP, pelo relato vivo da história da autonomia universitária que me transmitiu; ADALBERTO FISCHMANN, na Controladoria Geral da USP, por compartilhar a prática de quem lida diariamente com a questão da integridade universitária; e MARCO TUlIO VASCONCElOS, na Vice-Reitoria da Universidade Presbiteriana Mackenzie, pelo compartilhamento de suas experiências de gestão em universidades federais e privadas. 
Nas Arcadas, sou grato ao professor Fernando Dias MenEzes DE AlmeidA, especialmente por sua contribuição à pesquisa logo no início e durante a etapa de qualificação. Também pelo privilégio a mim concedido de coordenar as atividades de monitoria em suas aulas de Direito Administrativo. Sua incessante gentileza e cordialidade são inspiração para todos os seus alunos que querem seguir a carreira docente.

Ao professor José FERNANDO SIMÃO, a quem tenho o privilégio de chamar de amigo, pelos conselhos e constantes incentivos acadêmicos que me deu e me dá, mesmo sabendo que preferi seguir carreira no Direito Público ao invés do Direito Privado.

Ao professor Gustavo BAmBini, que durante o Mestrado manteve o papel de grande parceiro de artigos e pesquisas desde a minha graduação.

À professora MARIA PAULA DALLARI BUCCI, pelas oportunidades de pesquisa e publicações dentro dos temas de processo legislativo e políticas públicas, bem como às discussões sobre autonomia universitária.

Aos professores Elival da Silva Ramos e IgNÁcio PovedA, pela abertura que tiveram para ouvir minhas ideias e críticas sobre a integridade na gestão da USP, mesmo ocupando importantes cargos na Universidade.

À professora IRENE NOHARA, pelas observações e contribuições que fez à pesquisa durante seu desenvolvimento.

Aos amigos das Arcadas, pelas necessárias risadas e histórias que guardarei para sempre, aqui representados em parte por MARCELlo KAIRALLA, GUSTAVO GUIMARÃES, Mateus Naves, Cecília Cabrini, Mateus Coelho, Sérgio Montandon, Rafael DocAmpo, LuCAs Aluísio e CAIO DuARTE.

Aos também amigos das Arcadas, da turma da Representação Discente da PósGraduação, pelos intensos debates acadêmicos, discussões sobre modelos de ensino, de universidade e, por consequência, de minha dissertação, agradeço a MARCO ANTÔNIO Moraes Alberto, Alex Alckmin Zamboni, João Felipe BeZerra, Vivian Rocha e GuILHERME MeIRELLES. Tive, com o apoio de todos estes, o enorme privilégio de ter representado todos os pós-graduandos por dois anos na Congregação da Faculdade de Direito e na suplência do Conselho Universitário. 
Aos amigos da equipe de Teoria do Estado e colegas de orientação, pelo convívio semanal nas monitorias, aulas e, também, pelas muitas risadas, agradeço a Arthur Balbani, Letícia Tavares, Mirella Monteiro, Lucca lopes, Joẽo OtÁVIO PAEs DE BARRos, STEPHANE LIMA e NiNA NóBREGA.

A Gustavo Ungaro, Manuella Ramalho e Vera Wolff Bava, meus chefes no Governo do Estado de São Paulo, respectivamente na Ouvidoria Geral do Estado e na Corregedoria Geral da Administração, com os quais aprendi diariamente sobre integridade, transparência e controle, temas-chave da dissertação. Também aos demais colegas de trabalho destes órgãos, aos quais agradeço em nome da professora EUNICE PRUDENTE.

Aos professores Flávio de LeÃo Bastos Pereira e Michelle Asato JUNQUEIRA, por terem me aberto novas portas neste período de Mestrado.

A ANTÔNio CARlos de Freitas JR. e RicARdo EzEQuiEL ToRres, pelo convívio e aprendizado diários.

Ao professor ALEXANDRE SASSAKI, pelas colaborações com o trabalho na banca de qualificação.

Por fim, à Universidade de São Paulo, verdadeiro propósito da pesquisa, e ao povo paulista, que financia diariamente sua construção. 

"No universo da cultura o centro está em toda parte." (Miguel Reale)

"A forma democrática funda-se no pressuposto de que ninguém é tão desprovido de inteligência que não tenha contribuição a fazer às instituições e à sociedade a que pertence"

(Anísio Teixeira) 



\section{Resumo}

A autonomia das universidades brasileiras está em constante evolução. Originalmente, seu papel foi direcionado para a garantia das liberdades acadêmicas e da gestão de recursos próprios. Após crises e desequilíbrios fiscais que atingiram as universidades do país a partir do ano de 2013, houve uma evolução de seu conceito, passando-se a exigir maior grau de responsabilidade das instituições perante a sociedade que as mantém. Nesse contexto, é cada vez mais demandado que as universidades adotem práticas de integridade, promovendo a transparência, a responsabilidade fiscal e o controle interno, medidas inerentes ao Estado Democrático de Direito e aos princípios republicanos. A autonomia, assim, passa a ser importante instrumento para organização interna, planejamento, prestação de contas e reestruturação das universidades, visando sua própria preservação. Nesse sentido, a dissertação buscou identificar as normas e práticas de integridade aplicáveis às universidades e o impacto em sua autonomia. Para tanto, utilizou-se como objeto de estudo a Universidade de São Paulo e as medidas adotadas para a promoção da integridade a partir do ano de 2013. Ao final, foi realizada uma avaliação crítica com caráter propositivo sobre as práticas da universidade no que se refere aos aspectos estudados, com apresentação de propostas para seu aprimoramento.

Palavras-chave: Autonomia universitária. Integridade. Gestão universitária. Universidade. Ensino superior. 



\begin{abstract}
Brazilian universities' autonomy is in contínuous evolution. Its main role was originally directed towards to ensure academic freedom and management of its own resources. After fiscal unbalances that hit higher education institutions from 2013, there was an evolution of its concept, demanding universities encouragement be more responsible towards society. In this context, universities are more required to promote integrity and comply with transparency, fiscal responsibility and internal control laws, dealt aligned with Democratic Rule of Law and Republican principles. Thus, autonomy becomes an important widget for universities' internal organization, planning, accountability and restructuring, aiming at its own preservation. The research sought to study integrity norms and practices laid down by legislation concerning universities, as well as its autonomy impact. A complete diagnosis of Univeristy of São Paulo and tools adopted by it to promote integrity and compliance after 2013 was made. At the end, a constructive criticism assessment about university's integrity practices was performed, submitting recommendations for improvement.
\end{abstract}

Key-words: Univeristy autonomy. Integrity. University governance. University. Higher education. 



\section{SUMÁRIO}

APRESENTAÇÃ

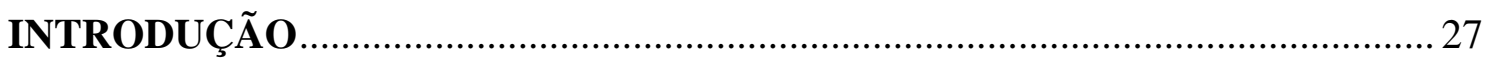

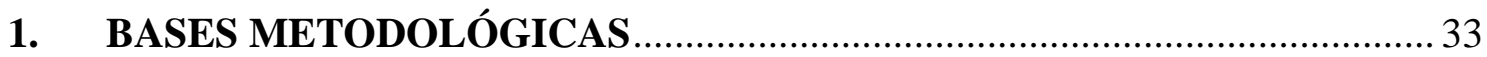

1.1. Objetivos, justificativa e metodologia empregada .................................. 33

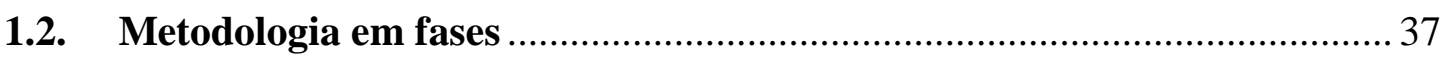

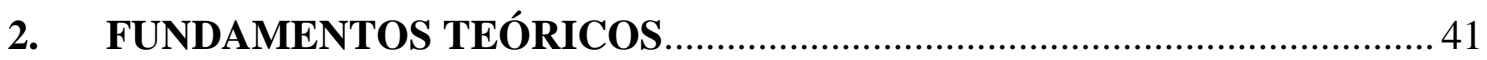

2.1. Conceitos e definições adotados ................................................................ 41

2.1.1. Integridade, conformidade e compliance …........................................... 41

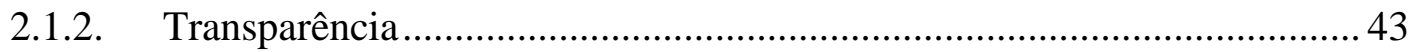

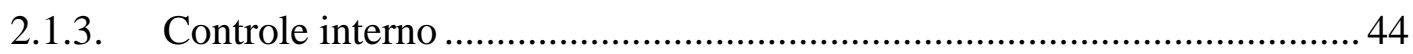

2.1.4. Eficiência e eficácia no Direito e na Ciência da Administração................ 44

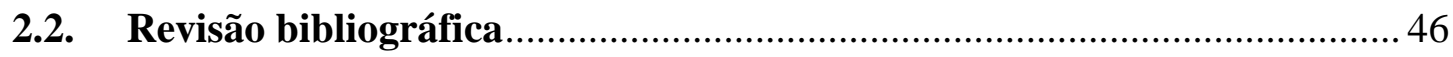

2.2.1. Transparência: princípio, valor, cultura ou objetivo da Administração?.. 46

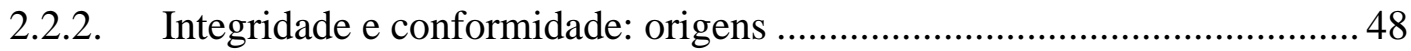

2.2.3. Integridade e conformidade como fatores mitigadores de responsabilidade

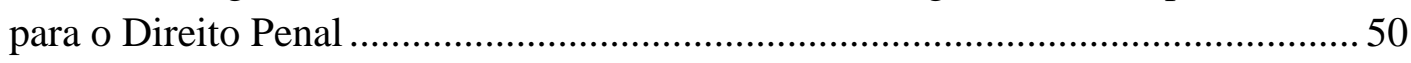

2.2.4. Compliance e integridade no ensino superior ..........................................53

2.2.5. Abordagens da Ciência da Administração ................................................ 54

2.2.6. O estudo e as pesquisas em gestão universitária......................................56

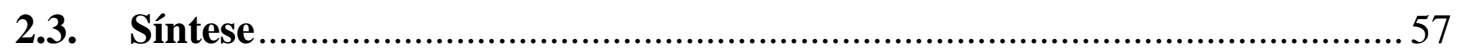

3. AS UNIVERSIDADES ESTADUAIS PAULISTAS E SUA AUTONOMIA:

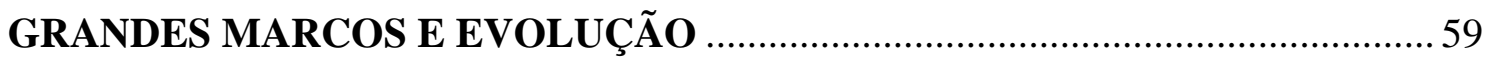

3.1. Da reforma da Lei $n^{0} 5.540 / 1968$ à Constituição Federal de 1988 ............. 59

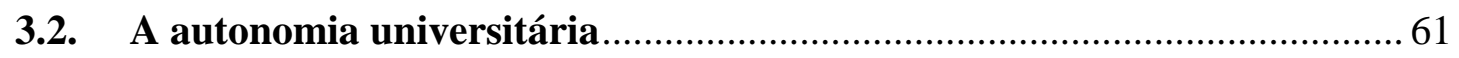

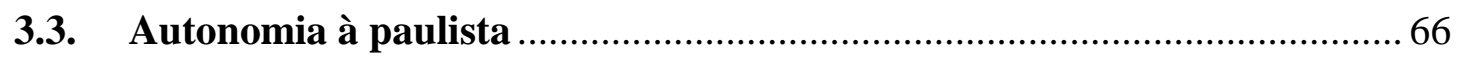

3.4. A nova autonomia e os desafios administrativos e acadêmicos das

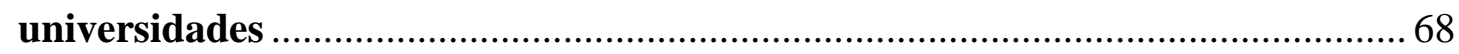

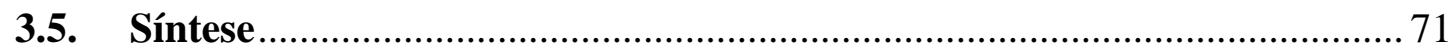

4. SISTEMAS DE INTEGRIDADE: PREVISÃO CONSTITUCIONAL E

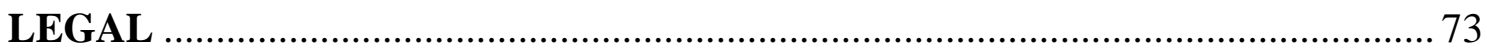

4.1. Estado, transparência e transparência de Estado ..................................... 73

4.1.1. Transparência ativa e passiva ................................................................. 76

4.2. Responsabilidade Fiscal e prestação de contas......................................... 79 
4.3. Controles internos e suas macrofunções ................................................ 82

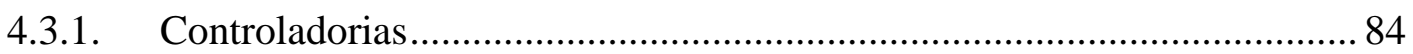

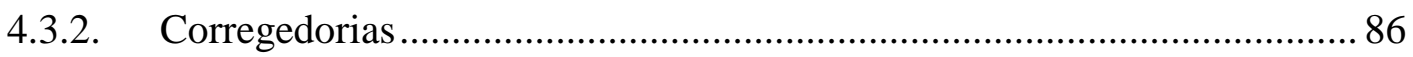

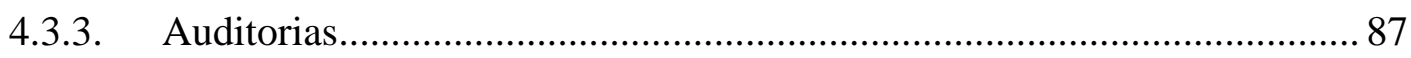

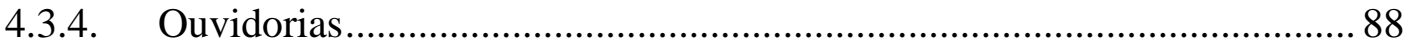

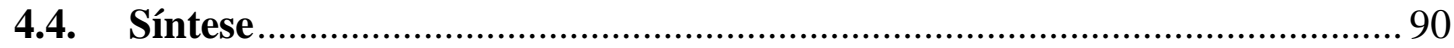

5. SISTEMA DE INTEGRIDADE DA UNIVERSIDADE DE SÃO PAULO ... 93

5.1. Transparência na universidade pública ................................................... 93

5.2. Panorama da responsabilidade fiscal ..................................................... 100

5.2.1. Os Parâmetros de Sustentabilidade Econômico-financeira como Lei de Responsabilidade Fiscal universitária .............................................................. 101

5.3. Organização e avaliação dos controles internos na USP ......................... 104

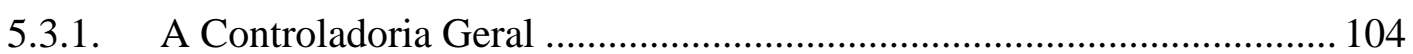

5.3.2. A ouvidoria universitária …................................................................ 107

5.3.3. O serviço de auditoria interna ................................................................. 109

5.3.4. Atividade correicional na universidade ................................................. 111

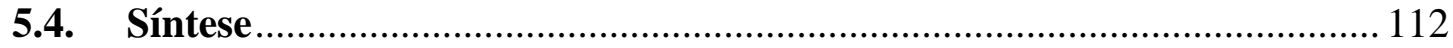

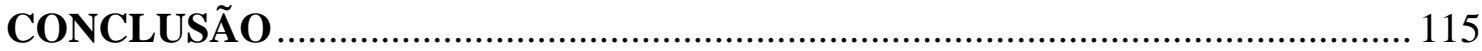

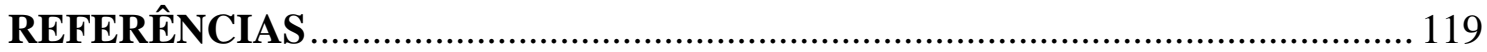

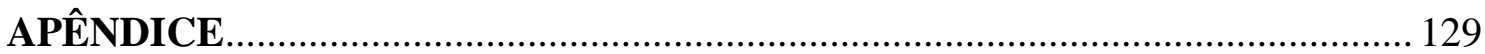




\section{APRESENTAÇÃO}

Inicio esta dissertação respondendo a três questionamentos preliminares. Assim que o recorte temático da dissertação foi acertado, envolvendo abordagens sobre a gestão universitária, realizei algumas reflexões não somente sobre o meu projeto de pesquisa, mas também de vida.

O primeiro aspecto para reflexão dizia respeito a como o projeto de pesquisa se inseria no meu projeto acadêmico. O segundo, em qual seria a minha contribuição diferenciada para a área em que atuo. O terceiro e último ponto para reflexão é relativo ao espaço de construção de conhecimento em que pretendo me inserir.

Para a primeira questão, o aspecto que mais pesou para a resposta é o planejamento para uma carreira docente que pretendo construir. Ao longo da graduação e desses anos de Pós-Graduação, tive a oportunidade de participar de muitas pesquisas, monitorias, extensões e atividades acadêmicas, muitas das quais pude colaborar na organização, sempre cercado por professores que me inspiram e me incentivam diariamente. Desta maneira, comecei a tomar gosto pela docência universitária.

Participei de gestões do Centro Acadêmico XI de Agosto e da Representação Discente que me abriram a possibilidade de diálogo e contato frequente com muitos alunos e professores, e consequentemente, a participação em inúmeros debates sobre o ensino jurídico, a estrutura e a governança universitária e a construção de diversos projetos acadêmicos. Este convívio e estas atividades foram intensificados inclusive durante a elaboração deste trabalho, quando fui honrado com o voto de meus pares para representá-los como membro da Congregação da Faculdade de Direito e como membro suplente do Conselho Universitário da USP.

Aqui vale ainda fazer uma pequena digressão: gosto sempre de mencionar uma deficiência de nossa Língua Portuguesa, que apesar de tão rica e completa, não possui vocábulos para diferenciar um professor de educação básica de um professor universitário. São todos professores. Diferentemente em outros idiomas, temos o teacher e o professor no inglês, o maestro e o professore no italiano, o enseñante e o profesor em espanhol, e também o ensegnant e o professeur em francês. 
A diferença, apesar de banal, carrega por trás dos termos dois papéis distintos entre esses docentes. Enquanto um professor de educação básica ensina, forma e participa do processo educacional de seus alunos, o professor universitário, além do ensino, possui outras atribuições, como a pesquisa e a cultura e extensão universitária, muitas vezes esquecidas.

Além disso, é esperado do professor de ensino superior que participe da gestão universitária em razão dos cargos que ocupa. Quanto mais graduado, titulado e experiente na carreira, crescem as atribuições do docente para que seja coordenador de curso, chefe de seu departamento, diretor de sua unidade, ou participe da gestão nos órgãos centrais da universidade. É possível ainda um menor grau de participação na gestão, mas não menos importante, como as participações em reuniões dos órgãos colegiados e decisórios de cada uma dessas esferas mencionadas, atribuições também crescentes em paralelo à titulação alcançada.

É nesse sentido que a resposta para a primeira pergunta se encaixa. Ingressei no mestrado e pretendo posteriormente ingressar no doutorado para me preparar para a vida docente. Além de desenvolver atividades de ensino, de pesquisa e de cultura e extensão universitária, pretendo sempre participar, na medida do possível, da gestão universitária, colaborando para o progresso das universidades.

O segundo ponto para reflexão era relativo à minha contribuição diferenciada para a área do conhecimento em que atuo. Essa questão parece ser mais objetiva e menos subjetiva do que a primeira. Para me auxiliar na elaboração da resposta, utilizeime da leitura do livro "Universidade em Movimento: Memória de uma Crise", que pude fazer nas férias de janeiro de 2018.

Após a leitura, alguns dos textos confirmaram minhas expectativas sobre o tratamento dos temas que pretendia estudar e me auxiliaram a construir uma linha para a pesquisa.

Mas afinal, como uma pesquisa sobre integridade na gestão universitária poderia ser diferenciada dos textos já escritos sobre estes assuntos? E mais: como poderia apresentar uma nova contribuição quando comparada àquelas de autoria de docentes

\footnotetext{
${ }^{1}$ MARCOVITCH, Jacques (Org.). Universidade em Movimento: Memória de uma Crise. São Paulo: Com-Arte; Fapesp, 2017.
} 
muito mais experientes, alguns inclusive já tendo participado da gestão de suas universidades? A resposta é simples, e confirmou-se após o início das pesquisas.

Em um dos diálogos que tive com a professora Nina Ranieri, suspeitamos inicialmente da possibilidade de que ainda não havia sido feita uma pesquisa que envolvesse padrões de integridade na gestão universitária sob o viés jurídico. Esta premissa se tornou uma das hipóteses do trabalho, que - como se verá ao longo do texto - foi confirmada, e é justamente a abordagem jurídica deste recorte da conformidade (a integridade) em um específico ente da administração pública (as universidades) que faz a contribuição ser diferenciada.

Busquei desenvolver um estudo de forma propositiva e sempre pensando de que modo poderia ajudar as universidades a serem cada vez mais prósperas ${ }^{2}$.

Desde a graduação tive a oportunidade de realizar pesquisas na área do Direito do Estado, envolvendo temas variados sobre direito à educação, direito educacional, ensino superior, entre outros, por acreditar que todos esses elementos são instrumentos imprescindíveis para o progresso e o desenvolvimento.

De igual maneira se deram todas as demais atividades acadêmicas que pude participar ao longo desses anos até aqui. Destaco as monitorias, grupos de estudos e de extensão, desenvolvidos nas áreas de Teoria do Estado, Direito Administrativo e Direito Constitucional.

Afinal, como diz a lenda, somente estudam o Estado e as instituições públicas aqueles que de fato querem trabalhar para melhorá-los e aperfeiçoá-los cada vez mais. De minha parte, isto se confirma.

Outro fator que possivelmente auxilia a abordagem dos temas é o fato de eu ter tido a oportunidade de atuar como assessor da Secretaria de Governo do Estado de São Paulo, atuando junto à Ouvidoria Geral do Estado na área técnica de transparência e acesso à informação. Durante este período, pude muito aprender sobre estes temas e

\footnotetext{
2 Preferi aqui utilizar "prósperas" ao invés de "melhores", por exemplo, porque este segundo termo apesar de se enquadrar neste contexto no sentido popular e comum - possui uma intensa carga de subjetivismo, principalmente quando se trata de avaliação do ensino superior, em que mesmo critérios e quesitos objetivos podem ser apenas reflexos da faceta subjetiva de quem avalia. O termo "prósperas", do contrário, pareceu-me menos subjetivista, deixando abertura para a possibilidade de cada instituição implantar as medidas que entender necessárias para a consecução de suas finalidades.
} 
contribuir diariamente para a promoção da transparência e integridade nos órgãos públicos estaduais.

Confesso que parte da inspiração para escrever este trabalho decorre da atuação junto ao Governo do Estado. Acredito, assim, que mesmo com pouco tempo de trajetória profissional, a visão de dentro da Administração - conhecendo a máquina pública e observando rotineiramente o funcionamento das instituições que atuam neste ramo - é certamente uma experiência diferenciada em relação à visão que pode ter um estudante ou pesquisador externo.

Deste modo, mesmo iniciando os estudos e as pesquisas de pós-graduação, que ainda terão toda uma vida acadêmica para serem aperfeiçoadas - e, quiçá, colocadas em prática -, a contribuição que darei pode ser diferenciada por estes fatores expostos.

Além disso, havia ainda um terceiro e último tópico que pude refletir antes de seguir em frente. Este dizia respeito ao espaço de construção do conhecimento em que pretendo me inserir.

A resposta também pode, a princípio, parecer simples. Contudo, uma análise e reflexão mais profundas fizeram-me acreditar que a pesquisa já parcialmente aqui introduzida pode representar muito mais do que um mero diagnóstico sobre a integridade em determinada universidade pública estadual.

É cediço que o que está posto em lei deve ser observado e seguido. As mais modernas normas sobre integridade, controle e transparência de entes públicos já existem no Brasil. Contudo, no Direito - e arrisco dizer, até em outras ciências humanas - dois mais dois podem não somar quatro. Mesmo que todo o sistema de controle ou de integridade esteja escrito no texto normativo, sua aplicação ou seu funcionamento podem não ter o desempenho esperado. Uma síntese de procedimentos, órgãos ou deveres estabelecidos em lei, por si só não refletem obrigatoriamente as necessidades ou a realidade prática dos entes públicos.

Tive a oportunidade de assistir, em março de 2019, a uma palestra do professor Giovanni Saavedra no II Seminário de Governança, Compliance e Cidadania da Universidade Presbiteriana Mackenzie, organizado pelos professores Irene Nohara e Flávio de Leão Bastos Pereira. Em sua exposição, o professor Saavedra fez reflexões que muito me instigaram: se tratarmos de compliance ou conformidade como um 
simples cumprimento de normas, então não haveria sequer necessidade de nos utilizarmos destes termos. Na sequência asseverou: nem sempre criar normas ou baixar códigos de conduta implica na diminuição de um risco.

Retomando o raciocínio: ora - é óbvio -, a Lei está posta para ser cumprida, mas nem sempre isso é sinônimo de integridade. É preciso algo mais para gerir os riscos e metabolizar as crises e problemas das universidades internamente, e quero demonstrar que a autonomia universitária é peça chave para isso, utilizando os resultados aqui obtidos para o aperfeiçoamento da gestão universitária.

Assim, é possível contribuir para que o diagnóstico realizado possa resultar em novos parâmetros de integridade, controle e transparência nas universidades públicas. E mais: é possível, também, evitar desequilíbrios financeiros e administrativos e projetar as universidades para seu futuro com maior segurança e previsibilidade, permitindo que esta cumpra sua missão para com a sociedade e desenvolva com plenitude, excelência e internacionalização suas atividades-fim de ensino, pesquisa, cultura e extensão. 


\section{INTRODUÇÃO}

Observamos, nos últimos anos, que as universidades estaduais paulistas (USP, UNESP e Unicamp) viveram grandes períodos de dificuldades, crises e desequilíbrios nas áreas financeira, administrativa e acadêmica, entre outras. Tais condições resultaram em enorme impacto em suas atividades-fim, comprometendo seu desempenho nas áreas de pesquisa, ensino, extensão, cultura e internacionalização.

Recente pesquisa feita por Alexandre Sassaki ${ }^{3}$ no âmbito da Universidade de São Paulo, que analisou os motivos do desequilíbrio financeiro da universidade entre os anos de 2010 e 2014, por exemplo, mostrou que o período, com o ápice de seus reflexos no ano de 2014, foi amplamente noticiado pela imprensa. Somente no ano de 2014, mais de 270 matérias sobre a crise da universidade foram produzidas apenas pelo jornal Folha de São Paulo ${ }^{4}$.

Ao menos no que diz respeito à USP, parte destes entraves está ligada a deficiências em sua gerência e inobservância de determinados padrões de governança, aliados, entre outros, ao aumento de suas despesas - decorrente do pagamento de prêmios, salários e benefícios -, e à queda de arrecadação tributária, que diminuiu a capacidade orçamentária da universidade ${ }^{5}$.

A obra "Universidade em Movimento: Memória de uma Crise", organizada pelo professor Jacques Marcovitch ${ }^{6}$, trouxe diversas visões sobre a mais recente crise vivida pela Universidade de São Paulo, cujos efeitos se observam até hoje.

Cito algumas delas: o texto de Vahan Agopyan e Rudinei Toneto Jr., sobre o desequilíbrio financeiro na $\mathrm{USP}^{7}$, o de Nina Ranieri sobre a questão da responsabilidade

\footnotetext{
${ }^{3}$ Cf. SASSAKI, Alexandre H. A Crise, suas Causas e seus Impactos. In: MARCOVITCH, Jacques (Org.). Universidade em Movimento: Memória de uma Crise. São Paulo: Com-Arte; Fapesp, 2017. pp. 131188. Para o trabalho completo, cf. SASSAKI, Alexandre Hideo. Governança e conformidade na gestão universitária. 2016. Tese (Doutorado em Administração) - Faculdade de Economia, Administração e Contabilidade, Universidade de São Paulo, São Paulo, 2016.

${ }^{4}$ Cf. SASSAKI, Alexandre H. A Crise, suas Causas e seus Impactos. In: MARCOVITCH, Jacques (Org.). Universidade em Movimento: Memória de uma Crise. São Paulo: Com-Arte; Fapesp, 2017. pp. 138.

${ }^{5}$ Cf. SASSAKI, Alexandre H. A Crise, suas Causas e seus Impactos. In: MARCOVITCH, Jacques (Org.). Universidade em Movimento: Memória de uma Crise. São Paulo: Com-Arte; Fapesp, 2017. p. 182.

${ }^{6}$ Cf. MARCOVITCH, Jacques (Org.). Universidade em Movimento: Memória de uma Crise. São Paulo: Com-Arte; Fapesp, 2017.

7 Cf. AGOPYAN, Vahan; TONETO JR., Rudinei. O Desequilíbrio Financeiro da USP. In: MARCOVITCH, Jacques (Org.). Universidade em Movimento: Memória de uma Crise. São Paulo: Com-Arte; Fapesp, 2017. pp. 31-50.
} 
fiscal nas universidades ${ }^{8}$ e os textos resultantes da tese de doutorado de Alexandre Sassaki, derivados de um estudo de caso sobre a governança universitária na USP entre 2010 e $2014^{9}$.

Este relatado desequilíbrio, contudo, não foi sentido apenas na USP, mas também nas demais universidades estaduais paulistas e nas federais. Em maio de 2017, o jornal O Estado de São Paulo noticiou que o Conselho de Reitores das Universidades Estaduais Paulistas - CRUESP deixaria de promover reajustes nos salários de seus servidores por conta de altos níveis de comprometimento de seu orçamento com a folha de pagamento. A matéria expôs que de $\mathrm{R} \$ 3,67$ bilhões recebidos pelas universidades nos primeiros cinco meses daquele ano, $\mathrm{R} \$ 3,69$ bilhões já haviam sido gastos apenas com salários ${ }^{10}$.

Em dezembro daquele mesmo ano, contudo, a Coordenadoria Geral de Administração - CODAGE da USP disponibilizou no Portal da Transparência da Universidade a planilha do CRUESP que demonstrava que a folha de pagamento de servidores já representava menos de $100 \%$ do orçamento das estaduais paulistas ${ }^{11}$. Em planilhas dos anos anteriores, é possível se observar um comprometimento com salários em valores superiores à receita.

Durante a última eleição para a reitoria da USP, nos meses finais de 2017, os então candidatos Vahan Agopyan e Antônio Carlos Hernandes - que se sagraram vencedores daquela disputa - afirmaram em seu programa de gestão que a universidade havia equilibrado suas contas e evitado a perda de sua autonomia, condição essencial para o exercício de sua missão. O reconhecimento de suas vulnerabilidades e as

8 Cf. RANIERI, Nina B. S. Autonomia Universitária e Lei de Responsabilidade Fiscal. In: MARCOVITCH, Jacques (Org.). Universidade em Movimento: Memória de uma Crise. São Paulo: Com-Arte; Fapesp, 2017. pp. 65-78.

${ }^{9}$ Cf. SASSAKI, Alexandre H. A Crise, suas Causas e seus Impactos. In: MARCOVITCH, Jacques (Org.). Universidade em Movimento: Memória de uma Crise. São Paulo: Com-Arte; Fapesp, 2017. pp. 131-188 e SASSAKI, Alexandre. Fundamentos Teóricos e Metodológicos. In: MARCOVITCH, Jacques (Org.). Universidade em Movimento: Memória de uma Crise. São Paulo: Com-Arte; Fapesp, 2017. pp. 189244.

${ }^{10} \mathrm{Cf}$. PALHARES, Isabela. Universidades paulistas propõem reajuste zero; USP quer reduzir jornada. $\mathbf{O}$ Estado de São Paulo. São Paulo, 30 mai. 2017. Disponível em: https://goo.gl/28gK1u. Acesso em 18 jul. 2018.

${ }^{11}$ Disponível em http://www.usp.br/codage/files/quad12-2017-fechamento.pdf. Acesso em 18 jul. 2018. 
medidas implementadas, por sua vez, serviriam para que tal quadro não se repetisse no futuro $^{12}$.

A autonomia então, como essencial para a consecução das finalidades das universidades, poderia restar seriamente em risco em virtude dos desequilíbrios financeiros que atingiram as instituições, comprometendo sua própria atuação. Nesse cenário, é altamente recomendável - senão imprescindível - que as universidades tenham maturidade e responsabilidade para que não voltem a correr tais riscos.

Esta, entretanto, não foi uma particularidade exclusiva da USP e tampouco das demais universidades brasileiras. Em todo o mundo, as instituições de ensino superior estão encontrando dificuldades no que tange ao seu financiamento e orçamento. Paralelamente a isso, também se aumentam mecanismos de controle e cobranças por prestação de contas.

Nos últimos anos, observamos um crescente aumento da desconfiança por parte da sociedade com as universidades públicas e sua autonomia ${ }^{13 ; 14}$, muito em parte por conta da falta de transparência e comunicação com a população.

Em entrevista ao programa Diálogos na USP, Nina Ranieri expõe a crescente demanda por prestação de contas e pela avaliação dos cursos superiores ${ }^{15}$ :

No mundo inteiro, seja universidade pública ou privada, cada vez mais se exige prestação de contas, se exige que as universidades mostrem para a sociedade o que estão fazendo. Esse é um fato mundial. Não por outras razões os rankings universitários têm tanto sucesso. Os rankings universitários traduzem, de forma muito simplificada, o que as universidades estão fazendo.

\footnotetext{
${ }^{12}$ Cf. AGOPYAN, Vahan; HERNANDES, Antônio Carlos. USP: Excelência para a Sociedade. Programa de gestão. p. 2. Disponível em: 〈https://goo.gl/C6gvGf〉. Acesso em 20 jul. 2018.

${ }^{13}$ Cf. RANIERI, Nina Beatriz Stocco; LUTAIF, Michel Kurdoglian. A autonomia universitária e seus percalços. Dossiê Universidade Pública. ComCiência - Revista Eletrônica de Jornalismo Científico [online]. 9 de jul. de 2019. Disponível em: <http://www.comciencia.br/autonomia-universitaria-e-seuspercalcos/>. Acesso em 27 de jul. de 2019.

${ }^{14}$ SCHWARTZMAN, Simon. Confiança e autonomia das universidades. O Estado de São Paulo. São Paulo, 10 mai. 2019. Disponível em <https://opiniao.estadao.com.br/noticias/espaco-aberto,confianca-eautonomia-das-universidades,70002822735>. Acesso em 10 mai. 2019.

${ }^{15}$ RANIERI, Nina Beatriz Stocco. "Diálogos na USP": a relevância e o futuro das universidades públicas. Jornal da USP. Entrevista concedida a Marcello Rollemberg. 24 mai. 2019. Disponível em: <https://jornal.usp.br/atualidades/dialogos-na-usp-abre-espaco-para-a-universidade-publica/>. Acesso em 24 mai. 2019.
} 
Vale dizer, a prestação de contas, a fiscalização por órgãos de controle e as exigências por maior transparência e responsabilidade fiscal não esbarram na previsão constitucional da autonomia universitária. A autonomia, pelo contrário, não se presta a fundar uma supremacia das universidades perante as demais normas e tampouco possui caráter absoluto $^{16}$. Pode - e inclusive deve - servir para que cada vez mais estas previsões e determinações sejam atendidas.

Ao menos no caso da Universidade de São Paulo, a autonomia foi essencial para a superação das dificuldades e a saída da crise, especialmente por meio da adoção e organização de mecanismos de integridade, entendidos aqui como as ferramentas que servem para o aprimoramento da gestão e bom uso dos recursos públicos, a exemplo da transparência, da responsabilidade fiscal e dos controles internos.

Este delicado quadro de dificuldades de gestão, contudo, não atinge somente as universidades, mas diversos tipos de organizações, tornando-se um problema mundial ${ }^{17}$. Marcelo Coimbra e Vanessa Manzi expuseram a crescente tendência de maior preocupação com a governança destas organizações e obediência a determinados padrões de integridade:

Ganhou força o movimento em favor da governança corporativa e com ele aprofundou-se a preocupação com a atuação das organizações não apenas conforme as normas legais, mas também de acordo com as melhores práticas decorrentes de valores e princípios como transparência, equidade, prestação de contas e responsabilidade. ${ }^{18}$

Assim, é crescente a demanda por integridade no âmbito dos entes públicos, tanto por seu aspecto relativo à probidade e à responsabilidade para com a coisa pública, quanto por seu aspecto moral e ético.

É possível, deste modo, o casamento entre universidades e mecanismos de integridade, celebrado por meio da autonomia universitária constitucionalmente garantida. As universidades, e em especial a USP, têm se valido da autonomia para

16 Explica Alexandre Santos de Aragão que, apesar da previsão da autonomia universitária, as universidades devem "prover cargos e contratar empregados mediante o prévio concurso público (art. 37, II) e devem se submeter ao teto constitucional", devendo ainda realizar licitações (art. 37, XXI) e submeter-se ao controle pelo Tribunal de Contas (art. 70). (A autonomia universitária no Estado contemporâneo e no direito positivo brasileiro. Rio de Janeiro: Ed. Lumen Juris, 2001. p. 91).

17 Cf. COIMBRA, Marcelo de Aguiar; MANZI, Vanessa Alessi (Orgs.). Manual de Compliance: Preservando a Boa Governança e a Integridade das Organizações. São Paulo: Atlas, 2010. p. xi.

18 COIMBRA, Marcelo de Aguiar; MANZI, Vanessa Alessi (Orgs.). Manual de Compliance: Preservando a Boa Governança e a Integridade das Organizações. São Paulo: Atlas, 2010. p. xi. 
reorganizar-se internamente e atender tanto às demandas legais quanto às demandas sociais por transparência, prestação de contas, responsabilidade fiscal, controles internos, entre outros.

Há ganhos recíprocos quando se trata de autonomia e de integridade. É possível dizer que por meio da autonomia fortalece-se a integridade, mediante a implementação de mecanismos e órgãos de acompanhamento, fiscalização e controle, por exemplo. Por outro lado, quanto mais as universidades zelarem pela boa gestão de seus recursos e mais apresentarem resultados à sociedade por meio da transparência, por exemplo, mais forte e inconteste se torna sua autonomia. 


\section{CONCLUSÃO}

Tornar empresas, organizações e universidades mais íntegras e vinculadas a normas de caráter moral e ético é uma tendência mundial. Percebe-se que além de zelar pela probidade e regularidade das práticas adotadas, a promoção da integridade traz inúmeras outras vantagens aos entes públicos e privados.

Em todo o mundo, as universidades públicas e privadas enfrentam problemas de financiamento. Ao mesmo tempo, cresce a demanda para que sejam mais transparentes, prestem contas e comuniquem suas atividades e sua atuação à comunidade. A autonomia, nesse sentido, é a ferramenta ideal para que se promovam essas práticas e valores na universidade, especialmente por meio de suas vertentes administrativa e de gestão financeira. Por muito tempo, entretanto, desde sua criação até 1988, as universidades brasileiras tiveram sua autonomia reduzida e seu conceito bastante esvaziado.

Desde a constitucionalização da autonomia universitária, três modelos de autonomia coexistem no País: o federal, os estaduais e o privado. O modelo federal, por exemplo, se distingue dos estaduais nas matérias que não são objeto de normas gerais de competência da União. Para as paulistas, ainda, há a peculiaridade do repasse anual de porcentagem fixa da arrecadação do ICMS no Estado, que permitiu ainda maior independência em relação ao Executivo. O modelo paulista, contudo, está embasado em um decreto estadual, instrumento normativo de competência do governador e com maior grau de precariedade em comparação às leis.

Constante em todos esses modelos, entretanto, é a natureza jurídica da autonomia, prerrogativa limitada que lhes permite autodeterminação, auto-organização e gerência de questões internas nas áreas didática, científica, administrativa, financeira e patrimonial, mantendo-se a observância do ordenamento jurídico nacional. Nesse sentido, as universidades não podem se escusar do cumprimento das demais leis.

Se em um primeiro momento, após 1988, o papel precípuo da autonomia era garantir a liberdade acadêmica e a proteção às intervenções do Governo na gestão e nas questões universitárias, nos últimos anos houve uma grande mudança do instituto. 
Os recentes desequilíbrios fiscais que atingiram as universidades brasileiras a partir do ano de 2013 trouxeram uma nova fase para a autonomia. No caso da USP, objeto de estudo dessa dissertação, foi preciso que a universidade se reinventasse, se reestruturasse e criasse mecanismos institucionais para atingir um reequilíbrio em suas contas, mediante planejamento interno e adoção de sistemas de integridade. Nesse contexto, as normas referentes ao controle, à transparência e à responsabilidade fiscal possuem cada vez mais apelo, contando com a autonomia para sua implantação.

As práticas de integridade, assim, não somente são inafastáveis da universidade, uma vez que esta é ente da Administração Pública, como também foram extremamente necessárias para a superação dos quadros de dificuldades financeiras enfrentados nos últimos anos. Deste modo, é esperado que a universidade, valendo-se de sua autonomia, se faça respeitá-las.

A transparência é valor intrínseco à democracia e ao republicanismo. Por meio dessa poderosa ferramenta, permite-se o acompanhamento da atividade dos órgãos públicos, fortalecendo a atuação das instituições e prestigiando o controle social. A ordem constitucional de 1988 fixou a publicidade como regra na atuação dos entes da Administração, incluindo-se aí as universidades, e o sigilo como exceção, aceitável apenas em restritas e excepcionais hipóteses, valorizando o interesse coletivo em detrimento do privado.

A avaliação da transparência na USP demonstra que houve avanços significativos nos últimos anos, principalmente a partir da entrada em vigência da Lei de Acesso à Informação. Há estruturação de um Portal da Transparência, que disponibiliza dados de interesse coletivo e geral ativamente, e um Serviço de Informações ao Cidadão regulamentado e alinhado à LAI. Alguns pontos, contudo, merecem aperfeiçoamento, em especial a falta de detalhamentos sobre as obras, contratos e diárias concedidas a servidores da universidade, assim como os prazos de atendimento dos pedidos de acesso.

Em relação às finanças públicas, o advento da Lei de Responsabilidade Fiscal em 2000 foi importante marco no que se refere ao equilíbrio das contas, por meio de normas e limites aplicáveis aos gastos do Estado, valorizando a prudência e a saúde financeira das instituições. 
Os Parâmetros de Sustentabilidade Econômico-financeira da USP, deste modo, apesar de baixados anos após da LRF, representam verdadeira lei de responsabilidade fiscal universitária, pensada e criada com fundamento na autonomia universitária. A norma seguiu as previsões da lei federal, determinando maior planejamento das finanças, prevendo limites e teto de gastos, criando travas institucionais para contenção de gastos, prestigiando a institucionalidade e a continuidade da gestão e fixando regramentos para a constituição de reservas de contingência.

Tal iniciativa é de extrema importância para a universidade, fortalecendo a própria autonomia e preservando o equilíbrio fiscal da instituição. A norma poderia, contudo, trazer maiores especificações sobre o planejamento plurianual, as diretrizes orçamentárias e o orçamento anual a que se refere.

Com relação ao controle interno, este não mais se limita à mera legalidade ou participação direta. É necessário que seja integrado e articulado entre seus vários órgãos, possuindo caráter multiprofissional, interdisciplinar e poroso, abrangendo diversas áreas do conhecimento, com competências bem definidas, sem que haja sobreposições de funções ou lacunas de atuação.

Nesse sentido, a criação de uma controladoria por meio da autonomia é a inauguração de uma nova fase para USP. O órgão se presta a monitorar e coordenar as atividades de controle interno da universidade, garantindo, deste modo, a promoção da integridade no âmbito interno, além de dialogar e cooperar institucionalmente com entidades de controle externo. Destaca-se também sua autonomia e independência funcional da CG, uma vez que não se encontra hierarquicamente vinculada à Reitoria, mas sim ao Conselho Universitário.

A ouvidoria universitária encontra-se estruturada e operante, sendo também atuante na transparência na universidade como uma das instâncias recursais de pedidos de acesso à informação. A criação da ouvidoria se deu já há alguns anos e tem demonstrado resultados positivos em seu papel de promotora do controle social, sendo o órgão universitário mais próximo da população e da comunidade universitária em geral.

O serviço de auditoria interna da USP realiza seu trabalho por demanda ou por amostragem, com enfoque na execução fiscal. Nunca foi realizada, contudo, auditoria geral em todas as unidades da Universidade, muito em parte por conta do reduzido 
tamanho da equipe responsável pela atividade. Tampouco foi contratada auditoria externa pela Reitoria, o que poderia apontar gargalos nos gastos da instituição e indicar padrões de atuação para o futuro.

Em relação à atividade correicional, esta é difusa e não possui um órgão responsável por sua coordenação. A criação de uma corregedoria, cartório ou secretaria de procedimentos correicionais, por exemplo, poderia centralizar a guarda de processos, fornecer apoio jurídico às atividades disciplinares e oferecer estrutura física para a condução dos procedimentos, tornando a atividade mais efetiva.

De modo geral, a Universidade de São Paulo tem feito bom uso de sua autonomia para promover reformas e as mudanças necessárias para se adequar às normas e padrões de integridade. Após o difícil quadro de crise dos últimos anos, foram criados órgãos, baixadas normas e promovidas reestruturações e práticas internas para que se evite a repetição daquele cenário. Alguns ajustes, contudo, ainda se fazem necessários, assim como um contínuo trabalho de acompanhamento e uma constante modernização para adaptação aos padrões que surgirem futuramente.

Deste modo, com transparência, responsabilidade, planejamento, controle e monitoramento, é possível garantir que a universidade não mais tenha suas atividades de ensino, pesquisa, cultura e extensão com excelência, impacto e internacionalização comprometidas em virtude de condições desfavoráveis. 


\section{REFERÊNCIAS}

AGOPYAN, Vahan; TONETO JR., Rudinei. O Desequilíbrio Financeiro da USP. In: MARCOVITCH, Jacques (Org.). Universidade em Movimento: Memória de uma Crise. São Paulo: Com-Arte; Fapesp, 2017. pp. 31-50.

AGOPYAN, Vahan; HERNANDES, Antônio Carlos. USP: Excelência para a Sociedade. Programa de gestão. p. 2. Disponível em: 〈https://goo.gl/C6gvGf>. Acesso em 20 jul. 2018.

ALMEIDA, Fernando Dias Menezes et al. (Coord.). Direito Público em evolução: estudos em homenagem à Professora Odete Medauar. Belo Horizonte: Fórum, 2013.

AMARAL FILHO, Marcos Jordão Teixeira do. O ombudsman e o controle da administração. São Paulo: EDUSP, 1993.

. Ouvidor-Geral: o ombudsman brasileiro. In: ALMEIDA, Fernando Dias

Menezes et al. (Coord.). Direito Público em evolução: estudos em homenagem à Professora Odete Medauar. Belo Horizonte: Fórum, 2013. pp. 275-281.

ANTUNHA, Heládio C. G. Universidade de São Paulo: Fundação e reforma. São Paulo São Paulo, CRPE - Estudos e Documentos, Série 1, vol. 10, 1974.

ARAGÃO, Alexandre Santos de. A autonomia universitária no Estado contemporâneo e no direito positivo brasileiro. Rio de Janeiro: Lumen Juris, 2001.

AZEVEDO, Antônio Junqueira de. Negócio jurídico: existência, validade e eficácia. 4. ed. São Paulo: Saraiva, 2002.

AZEVEDO, David Teixeira; AZEVEDO, André Dias. A lei anticorrupção e os programas de compliance. In: SILVEIRA, Renato de Mello Jorge; RASSI, João Daniel (Orgs.). Estudos em homenagem a Vicente Greco Filho. São Paulo: LiberArs, 2014.

AZEVEDO, Ivan Almeida de; JACOBSEN, Alessandra de Linhares. Ações de controle interno na Universidade Federal de Santa Catarina na perspectiva do gerenciamento de riscos. In: XV Colóquio Internacional de Gestão Universitária, Mar del Plata, dez. 2015.

BALBACHEVSKY, Elizabeth. Stuart Mill: liberdade e representação. In: WEFFORT, Francisco C. (Org.). Os Clássicos da Política 2. São Paulo: Ática, 2001.

BALBANI, Arthur Paku Ottolini. Controle de constitucionalidade e Poder Legislativo: análise do controle preventivo de constitucionalidade dos atos parlamentares. 2019. Tese de Láurea (Graduação em Direito) - Faculdade de Direito, Universidade de São Paulo, 2019.

BLIACHERIENE, Ana Carla; RIBEIRO, Renato. J. Fiscalização financeira e orçamentária: controle interno, controle externo e controle social do orçamento. In: CONTI, José Maurício; SCAFF, Fernando Facury. (Org.). Orçamentos Públicos e Direito Financeiro. $1^{a}$ ed. São Paulo: Revista dos Tribunais, 2011, p. 1209-1233. 
BLIACHERIENE, Ana Carla; FUNARI, Marcos. H.; RIBEIRO, Renato J. B. Governança pública, eficiência e transparência na administração pública. In: Fórum de Contratação e Gestão Pública (Impresso), v. 12, p. 9-15, 2013.

BOBBIO, Norberto. Teoria geral da política: a filosofia política e as lições dos clássicos. Rio de Janeiro: Elsevier, 2000.

BRANDÃO, Joseth Ferreira. Sistemas de controle interno e transparência pública: Estudo de caso da Universidade Federal de Alagoas. 2015. Dissertação (Mestrado em Ciências Contábeis, Atuariais e Finanças) - Pontifícia Universidade Católica de São Paulo, 2015.

BRESSER-PEREIRA, Luiz Carlos. A Reforma do Estado nos anos 90: lógica e mecanismos de controle. Lua Nova, v.45, p.49-95, 1998.

CAMPOS, Ernesto de Souza. História da Universidade de São Paulo. São Paulo: [s.n.], 1954.

CANDELORO, Ana Paula P.; DE RIZZO, Maria Balbina Martins; PINHO, Vinícius. Compliance $360^{\circ}$ : riscos, estratégias, conflitos e vaidades no mundo corporativo. São Paulo: Trevisan Editora Universitária, 2012.

CARDOSO, Débora Motta. Criminal compliance na perspectiva da lei de lavagem de dinheiro. São Paulo: LiberArs, 2015.

CASTRO, Patrícia Reis Carvalho de. Um estudo sobre o processo de adesão ao programa de integridade da lei 12.846 , de $1^{\circ}$ de agosto de 2013 , e seus efeitos sobre os controles internos em empresas nacionais e multinacionais. 2016. Dissertação (Mestrado em Controladoria e Contabilidade: Contabilidade) - Faculdade de Economia, Administração e Contabilidade, Universidade de São Paulo, São Paulo, 2016.

CHAIMOVICH, Hernan. Universidades públicas paulistas e o Estado de São Paulo in Jornal da USP. 16 mai. 2019. Disponível em: <jornal.usp.br/?p=245741>. Acesso em 17 mai. 2019.

COIMBRA, Marcelo de Aguiar; MANZI, Vanessa Alessi (Orgs.). Manual de Compliance: Preservando a Boa Governança e a Integridade das Organizações. São Paulo: Atlas, 2010.

COLLI, Walter. Gestão e política na universidade pública. Revista da Universidade de São Paulo, São Paulo, n.78, pp. 14-21, 2008.

COLOMBO, Sônia Simões. Planejamento estratégico. In: COLOMBO, Sônia Simões et al. Gestão educacional: uma nova visão. Porto Alegre: Artmed, 2004.

COLOMBO, Sônia Simões; RODRIGUES, G. M (Orgs.). Desafios da gestão universitária contemporânea. Porto Alegre: Artmed, 2011.

CONACI - Conselho Nacional de Controle Interno. Panorama do Controle Interno no Brasil. Brasília, 2014.

CONTROLADORIA GERAL DA UNIÃO. Metodologia e critérios de avaliação: EBT 360. 1.ed. Brasília, 2019. Disponível em: 〈http://bit.do/eSLQv>. Acesso em 17 mai. 2019. 
$1^{\text {a }}$ Ed. Brasília, 2013.

Manual da Lei de Acesso à Informação para Estados e Municípios.

COVAC, José Roberto; SILVA, D. C. Compliance como boa prática de gestão no ensino superior privado. São Paulo: Saraiva, 2015.

CRUZ, Hélio Nogueira da. Autonomia e recursos orçamentários do Estado. In: CALDAS, Marília Junqueira (Org.). A USP e seus desafios: I Fórum de Políticas Universitárias: módulos 2 e 3. São Paulo: EDUSP, 2001. pp. 127-134.

CUNHA, Luís Antônio. A Universidade Reformanda: O golpe de 64 e a modernização do ensino superior. 2.ed. São Paulo: UNESP, 2007.

A Universidade Temporã: $O$ ensino superior, da Colônia à Era Vargas. 3.ed. São Paulo: UNESP, 2007.

CURY, Carlos Roberto Jamil. Gestão democrática da educação: exigências e desafios. Revista Brasileira de Política e Administração da Educação, v. 18, n. 2. jul./dez. 2002.

DI PIETRO, Maria Sylvia Zanella; SUNDFELD, Carlos Ari (Orgs.). Controle da administração, processo administrativo e responsabilidade do Estado (Coleção doutrinas essenciais: Direito Administrativo, v.3). São Paulo: Editora Revista dos Tribunais, 2012.

DI PIETRO, Maria Sylvia Zanella. Direito Administrativo. 27.ed. São Paulo: Atlas, 2014.

DURHAM, Eunice Ribeiro. A autonomia universitária - extensão e limites. Núcleo de Estudos sobre Ensino Superior. São Paulo, 2005. Disponível em: < http://nupps.usp.br/downloads/docs/dt0503.pdf>. Acesso em 14 jan. 2019.

O Projeto de Reforma do Ensino Superior. Núcleo de Pesquisas sobre o Ensino Superior. São Paulo, 2005.

EHRHARD, Werner; JENSEN, Michael C.; ZAFFRON, Steve. Integrity: a positive model that incorporate the normative phenomena of morality, ethics and legality. Harvard Business School NOM Working Paper No. 06-11, mar. 2009. Disponível em <https://papers.ssrn.com/sol3/papers.cfm?abstract_id=920625>. Acesso em 29 mai. 2018.

FÁVERO, Maria de Lourdes A. A universidade brasileira em busca de sua identidade. Petrópolis: Vozes, 1977.

FERNANDES, Florestan. Universidade Brasileira: Reforma ou Revolução? São Paulo: Alfa-Ômega, 1975.

FERRAZ, Anna Cândida da Cunha. A autonomia universitária na Constituição de 05.10.1988. Revista da Procuradoria Geral do Estado de São Paulo, São Paulo, edição especial, pp. 87-124, set. 1998. Disponível in http://www.pge.sp.gov.br/centrodeestudos/revistaspge/revista/tes5.htm. Acesso em 30 ago. 2018.

GIOVANINI, Wagner. Compliance: a excelência na prática. São Paulo, 2014. 
GOLDEMBERG, José. Reflexões sobre a crise da USP. Depoimento. Instituto de Estudos Avançados da USP, 2014. Disponível em: <http://iptv.usp.br/portal/video.action?idItem=24368>. Acesso em 01 out. 2018.

GOLDWORTH, Ammon (Org.). The collected works of Jeremy Bentham. Londres: Oxford, 1983.

GORGA, Maria Luiza. Minimizando riscos - compliance penal para o profissional da medicina. 2016. Dissertação (Mestrado em Direito Penal) - Faculdade de Direito, Universidade de São Paulo, São Paulo, 2016.

GURGEL, Claudio; JUSTEN, Agatha. Controle social e políticas públicas: a experiência dos Conselhos Gestores. Rev. Adm. Pública, Rio de Janeiro, v. 47, n. 2, p. 357-378, abr. 2013.

HEINEN, Juliano. Comentários à Lei de Acesso à Informação: Lei no 12.527/2011. Belo Horizonte: Fórum, 2014.

INSTITUTO ETHOS. Sistemas de Integridade nos Estados brasileiros. 1.ed. São Paulo, 2012.

ISSA, Rafael Hamze. O controle judicial dos atos normativos das agências reguladoras. 2015. Dissertação (Mestrado em Direito do Estado) - Faculdade de Direito, Universidade de São Paulo, São Paulo, 2015).

JUNQUEIRA, Michelle Asato; PINTO, Felipe Chiarello de Souza. Teoria da Constituição: a formação do Estado constitucional e o constitucionalismo brasileiro. São Paulo: Editora Mackenzie, 2018.

JUSTEN FILHO, Marçal. Curso de Direito Administrativo. 12.ed. São Paulo: Editora Revista dos Tribunais, 2016.

KRASILCHIK, Myriam. Gestão - desafios e perspectivas. Revista da Universidade de São Paulo (EDUSP), São Paulo, n. 78, pp. 22-31, 2008.

LOUREIRO, Maria Amélia Salgado. (Coord.). História das Universidades. São Paulo: Estrela Alfa Editora, 1986.

LOUREIRO, Maria Rita et al. Do controle interno ao controle social: a múltipla atuação da CGU na democracia brasileira. Cadernos Gestão Pública e Cidadania, São Paulo, vol.17, n. 60, pp. 54-67, jan./jun. 2012.

LUTAIF, Michel Kurdoglian. A autonomia universitária na visão do Supremo Tribunal Federal. Monografia apresentada à Escola de Formação da Sociedade Brasileira de Direito Público. São Paulo, 2014. Disponível em: <http://www.sbdp.org.br/arquivos/monografia/261_Michel\%20Lutaif.pdf>. Acesso em: 30 jan. 2018.

LUZ, Ilana Martins. A responsabilidade penal por omissão e os programas de compliance. 2017. Tese (Doutorado em Direito Penal) - Faculdade de Direito, Universidade de São Paulo, São Paulo, 2017.

MALISKA, Marcos Augusto. O direito à educação e a Constituição. Porto Alegre: Fabris, 2001. 
MANZI, Vanessa Alessi. Compliance no Brasil: consolidação e perspectivas. São Paulo: Saint Paul Editora, 2008.

MARCOVITCH, Jacques. A Universidade (Im)possível. São Paulo: Futura, 1998.

A Revolução Acadêmica. Revista da Universidade de São Paulo (EDUSP), São Paulo, n. 78, pp. 6-13, 2008.

Universidade em movimento. Revista da Universidade de São Paulo, n. 105. abr./jun. 2015. pp. 43-50.

. (Org.). Universidade em movimento: Memória de uma crise. São Paulo: Com-Arte; FAPESP, 2017.

A missão acadêmica e seus valores. In: Universidade em movimento: Memória de uma crise. São Paulo: Com-Arte; FAPESP, 2017. pp. 15-30.

pp. 7-15, abr. 2018

Como salvar a política? Estudos Avançados, São Paulo, vol. 32, n. 92,

MARQUES NETO, Floriano de Azevedo. Os grandes desafios do controle da Administração Pública. In: Fórum de Contratação e Gestão Pública - FCGP, ano 9, n. 100, abr. 2010. Belo Horizonte: Fórum, 2010. pp. 7-30.

Punir universidade por conhecimento que não convém ao governo é inconstitucional, diz Diretor do Direito da USP. BBC News Brasil. Entrevista concedida a Letícia Mori. 02 mai. 2019. Disponível em: <https://www.bbc.com/portuguese/brasil-48130548>. Acesso em 02 mai. 2019.

MEDAUAR, Odete. Controle da Administração Pública. 2. ed. São Paulo: Revista dos Tribunais, 2012.

Tribunais, 2016 .

Direito administrativo moderno. 20. ed. São Paulo: Revista dos

O Direito Administrativo em Evolução. 3.ed. Brasília: Gazeta

Jurídica, 2017.

MEIRELLES, Hely Lopes. A administração pública e seus controles. In: DI PIETRO, Maria Sylvia Zanella; SUNDFELD, Carlos Ari (Orgs.). Controle da administração, processo administrativo e responsabilidade do Estado (Coleção doutrinas essenciais: Direito Administrativo, v.3). São Paulo: Editora Revista dos Tribunais, 2012. pp. 67-78.

MENDES, Gilmar Ferreira. Arts. 48 a 59. In: MARTINS, Ives Gandra da Silva; NASCIMENTO, Carlos Vander do. Comentários à Lei de Responsabilidade Fiscal. São Paulo: Saraiva, 2012.

MICHENER, Gregory; CONTRERAS, Evelyn; NISKIER, Irene. Da opacidade à transparência? Avaliando a Lei de Acesso à Informação no Brasil cinco anos depois. Revista de Administração Pública, Rio de Janeiro, v. 52, n. 4, p. 610-629, jul. 2018. Disponível em: <http://bibliotecadigital.fgv.br/ojs/index.php/rap/article/view/75716/72524>. Acesso em: 15 Dez. 2019. 
MORAES, Reginaldo C.; SILVA, Maitá de Paula; CASTRO, Luiza Carnicero de. Modelos internacionais de educação superior: Estados Unidos, Alemanha e França. São Paulo: Editora UNESP, 2017.

MUZY, Paulo de Tarso Artencio; DRUGOWICH, José Roberto. Os desafios da autonomia universitária: História recente da USP. Jundiaí: Paco Editorial, 2018.

NASCIMENTO, Carlos Vander do. Arts. $1^{\circ}$ a 17. In: MARTINS, Ives Gandra da Silva; NASCIMENTO, Carlos Vander do. Comentários à Lei de Responsabilidade Fiscal. São Paulo: Saraiva, 2012.

NEGRÃO, Célia; PONTELO, Patrícia. Compliance, controle interno e riscos: a importância da área de gestão de pessoas. Brasília: Editora SENAC, 2014.

NOHARA, Irene Patrícia. Reforma administrativa e burocracia: Impacto da eficiência na configuração do Direito Administrativo brasileiro. 2011. Tese (LivreDocência em Direito Administrativo) - Faculdade de Direito, Universidade de São Paulo, São Paulo, 2011.

NUNES, Eliane Pereira; CORONEL, Daniel Arruda. O controle interno como instrumento de gerenciamento na Universidade Federal do Pampa. Estudo \& Debate, Lajeado, v. 20, n. 1, pp. 143-160, 2013.

OLIVEIRA, Gustavo Justino de; SOUZA, Otavio Augusto Venturini de. ControladoriaGeral da União: uma agência anticorrupção? In: PEREZ, Marcos Augusto; SOUZA, Rodrigo Pagani de. Controle da administração pública. Belo Horizonte: Fórum, 2017.

OLIVEIRA, Licurgo Joseph Mourão de. Orçamento público biopolítico: Corrupção, transparência e efetividade dos gastos. 2016. Tese (Doutorado em Direito Econômico, Financeiro e Tributário) - Faculdade de Direito, Universidade de São Paulo, São Paulo, 2016.

OTAVIANI, Márcia Cristina. Chrestomathia: Arte e Ciência para Jeremy Bentham. 2012. Tese (Doutorado em História da Ciência) - Pontifícia Universidade Católica de São Paulo, São Paulo, 2012.

PALHARES, Isabela. Universidades paulistas propõem reajuste zero; USP quer reduzir jornada. O Estado de São Paulo. São Paulo, 30 mai. 2017. Disponível em: <https://goo.gl/28gK1u>. Acesso em 18 jul. 2018.

PEREZ, Marcos Augusto. A administração pública democrática: Institutos de participação popular na administração pública. Belo Horizonte: Fórum, 2009.

PEREZ, Marcos Augusto; SOUZA, Rodrigo Pagani de. Controle da administração pública. Belo Horizonte: Fórum, 2017.

PILETTI, Nelson. História da Educação no Brasil. São Paulo: Ática, 1990.

POLIZEL, Caio; STEINBERG, Herbert. Governança Corporativa na Educação Superior: casos práticos de instituições privadas (com e sem fins lucrativos). 1.ed. São Paulo: Saraiva, 2013. 
QUEIROZ, Christina. Modelos Recriados: Configuração atual das instituições brasileiras de ensino superior reflete a incorporação de arranjos universitários de distintos países. Revista Pesquisa FAPESP, São Paulo, n. 277, pp. 26-29, mar.2019.

RAMOS, Mozart Neves. Ensino Superior no Brasil: Expansão e avaliação do sistema universitário. In: BOSI, Alfredo et al. Universidade: panorama e perspectivas. Cadernos Adenauer. São Paulo: Fundação Konrad Adenauer, 2000. pp. 27-8.

RAMOS FILHO, Carlos Alberto de Moraes. Responsabilidade fiscal: Aspectos fundamentais da Lei Complementar nº 101/2000. Manaus: Ed. Caminha, 2002.

RANIERI, Nina Beatriz Stocco. Autonomia universitária: as universidades públicas e a Constituição Federal. 1.ed. São Paulo: EDUSP, 1994.

- A Universidade e o Estado: algumas considerações acerca do papel do Estado na atividade educacional de nível superior. Cadernos de Direito Constitucional e Ciência Política (Revista dos Tribunais), São Paulo, v. 6, n.24, p. 63-71, 1998.

Educação Superior, Direito e Estado. São Paulo: EDUSP, 2000.

O Estado democrático de direito e o sentido da exigência de preparo da pessoa para o exercício da cidadania, pela via da educação. Tese (LivreDocência em Direito) - Faculdade de Direito da Universidade de São Paulo, São Paulo, 2009.

. Autonomia universitária: As universidades públicas e a Constituição Federal de 1988. São Paulo: Imprensa Oficial, 2013.

Autonomia universitária e Lei de Responsabilidade Fiscal. In: MARCOVITCH, Jacques (Org.). Universidade em movimento: Memória de uma crise. São Paulo: Com-Arte; FAPESP, 2017. pp. 65-78.

"Diálogos na USP": a relevância e o futuro das universidades públicas.

Jornal da USP. Entrevista concedida a Marcello Rollemberg. 24 mai. 2019. Disponível em: <https://jornal.usp.br/atualidades/dialogos-na-usp-abre-espaco-para-a-universidadepublica/>. Acesso em 24 mai. 2019.

RANIERI, Nina Beatriz Stocco; LUTAIF, Michel Kurdoglian. A autonomia universitária e seus percalços. Dossiê Universidade Pública. ComCiência - Revista Eletrônica de Jornalismo Científico. 09 de jul. de 2019. Disponível em: <http://www.comciencia.br/autonomia-universitaria-e-seus-percalcos/>.

REALE, Miguel. Reforma Universitária: subsídios para a sua implantação. São Paulo: Convívio, 1985.

RIBEIRO, Ana Maria de Almeida. A necessária transparência pública na UFRJ para uma gestão democrática. Práticas em Gestão Pública Universitária, [online], v. 1, n. 2, pp. 410-437, jun./dez. 2017. Disponível em <https://revistas.ufrj.br/index.php/pgpu/article/view/4244/9269>. Acesso em $15 \mathrm{dez}$. 2019.

RIBEIRO, Antonio Silva Magalhães. Corrupção e controle na administração pública brasileira. São Paulo: Atlas, 2004. 
RIGHETTI, Sabine. Qual é a melhor? Origem, indicadores, limitações e impactos dos rankings universitários. 2016. Tese (Doutorado em Política Científica e Tecnológica) Instituto de Geociências, Universidade Estadual de Campinas, Campinas, 2016.

SALVADOR NETTO, Alamiro Velludo. Responsabilidade Penal da Pessoa Jurídica. 2017. Tese (Titularidade em Direito Penal) - Faculdade de Direito, Universidade de São Paulo, São Paulo, 2017.

SARCEDO, Leandro. Compliance e responsabilidade penal da pessoa jurídica: construção de um novo modelo de imputação baseado na responsabilidade corporativa. São Paulo: LiberArs, 2016.

SASSAKI, Alexandre Hideo. Governança e conformidade na gestão universitária. 2016. Tese (Doutorado em Administração) - Faculdade de Economia, Administração e Contabilidade, Universidade de São Paulo, São Paulo, 2016.

SASSAKI, Alexandre H. A Crise, suas Causas e seus Impactos. In: MARCOVITCH, Jacques (Org.). Universidade em Movimento: Memória de uma Crise. São Paulo: Com-Arte; Fapesp, 2017. pp. 131-188.

SASSAKI, Alexandre. Fundamentos Teóricos e Metodológicos. In: MARCOVITCH, Jacques (Org.). Universidade em Movimento: Memória de uma Crise. São Paulo: Com-Arte; Fapesp, 2017.

SCAFF, Fernando Facury. O homem deve vir em primeiro lugar na análise do Direito Financeiro. Consultor Jurídico. 31 de out. de 2017. Disponível em: $<$ https://www.conjur.com.br/2017-out-31/contas-vista-homem-vir-primeiro-lugaranalise-direito-financeiro>. Acesso em 14 de abr. de 2019.

- Notas para a compreensão do Direito Financeiro como um Direito Social. In: KZAN NETO, Calilo Jorge; SILVA, Maria Stela Campos; NEVES, Rafaela Teixeira Sena (Orgs.). Tributação e Direitos Humanos. Lumen Juris: Rio de Janeiro, 2018. pp. 3-14.

SCHIRATO, Renata Nadalin Meireles. Transparência administrativa, participação, eficiência e controle social: direito administrativo em evolução? In: ALMEIDA, Fernando Dias Menezes et al. (Coord.). Direito Público em evolução: estudos em homenagem à Professora Odete Medauar. Belo Horizonte: Fórum, 2013.

SCHIRATO, Vitor Rhein. O controle interno da administração pública e seus mecanismos. Revista dos Tribunais, n. 956, pp. 25-50, jun. 2015.

SCHWARTZMAN, Simon. A autonomia universitária e a Constituição de 1988. Folha de São Paulo. São Paulo, 12 dez. 1988. Disponível em <http://www.schwartzman.org.br/simon/cont88.htm>. Acesso em 14 jan. 2019.

. Confiança e autonomia das universidades. O Estado de São Paulo. São Paulo, 10 mai. 2019. Disponível em <https://opiniao.estadao.com.br/noticias/espacoaberto,confianca-e-autonomia-das-universidades,70002822735>. Acesso em 10 mai. 2019. 
SCHWARTZMAN, Simon; DURHAM, Eunice Ribeiro; GOLDEMBERG, José. A Educação no Brasil em uma perspectiva de transformação. Núcleo de Pesquisas sobre Ensino Superior. Universidade de São Paulo. São Paulo, 1993.

SILVEIRA, Renato de Mello Jorge; SAAD-DINIZ, Eduardo. Compliance, Direito Penal e Lei Anticorrupção. São Paulo: Saraiva, 2015.

UNGARO, Gustavo; CARVALHO, Guilherme Siqueira de. Participação, controle e transparência por meio das ouvidorias públicas. In: BASSOTTI, Ivani Maria; SANTOS, Thiago Souza (Orgs.). Tópicos essenciais sobre gestão pública. São Paulo: EGAP, 2016. pp. 289-312.

UNIVERSIDADE DE SÃO PAULO. Relatório de gestão da Ouvidoria Geral 20142017. Disponível em: shorturl.at/aehJZ. Acesso em 14 de ago. de 2019.

Relatório de atividades da Controladoria Geral da Universidade de São Paulo. Janeiro de 2018 a dezembro de 2018. 2018. Disponível em: shorturl.at/kvwG9. Acesso em 01 set. 2019.

YIN, Robert K. Estudo de caso: planejamento e métodos. 2. ed. Porto Alegre: Bookman, 2001. 
APÊNDICE 
CHECKLIST EBT-360 - Simulação USP

\begin{tabular}{|c|c|c|c|c|c|c|c|c|}
\hline Ordem & \multicolumn{2}{|c|}{ Detalhamento } & \multicolumn{2}{|c|}{ Temas/Parâmetros } & \multirow{2}{*}{$\begin{array}{c}\text { Pontuação } \\
\text { máxima }\end{array}$} & \multirow{2}{*}{$\begin{array}{c}\text { Informação } \\
\text { localizada? } \\
\text { (Sim ou Não) } \\
\text { Sim }\end{array}$} & \multirow{2}{*}{\begin{tabular}{r|} 
Pontuação \\
1,5
\end{tabular}} & \multirow{2}{*}{$\begin{array}{c}\% \\
1,50 \%\end{array}$} \\
\hline 1 & & & Estrutura organizacior & & & & & \\
\hline \multirow{3}{*}{2} & & 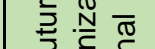 & & Endereço & 0,70 & Não & 0 & \multirow{3}{*}{$2,10 \%$} \\
\hline & & 름 ত్ 등 & Unlaades & Telefone & 0,70 & Não & 0 & \\
\hline & & & & Horário de atendimento & 0,70 & Não & 0 & \\
\hline \multirow{3}{*}{3} & \multirow{3}{*}{\multicolumn{2}{|c|}{ 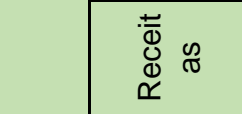 }} & \multirow{3}{*}{ Dados das receitas } & Previsão & 1,00 & Sim & 1 & \multirow{3}{*}{$4,00 \%$} \\
\hline & & & & Arrecadação & 1,50 & Sim & 1,5 & \\
\hline & & & & Classificação & 1,50 & Não & 0 & \\
\hline \multirow{5}{*}{4} & \multirow{11}{*}{\multicolumn{2}{|c|}{ 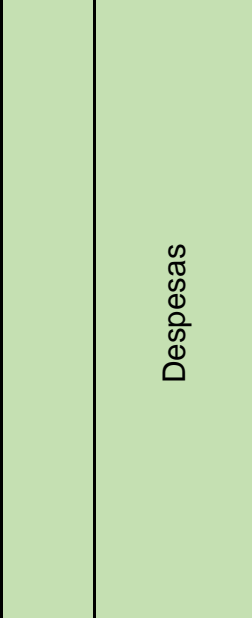 }} & \multirow{5}{*}{ Empenhos } & Número & 0,80 & Sim & 0,8 & \multirow{11}{*}{$12,00 \%$} \\
\hline & & & & Valor & 0,80 & Sim & 0,8 & \\
\hline & & & & Data & 0,80 & Não & 0 & \\
\hline & & & & Favorecido & 0,80 & Sim & 0,8 & \\
\hline & & & & Descrição & 0,80 & Sim & 0,8 & \\
\hline \multirow{4}{*}{5} & & & \multirow{4}{*}{ Pagamentos } & Valor & 1,00 & Sim & 1 & \\
\hline & & & & Data & 1,00 & Não & 0 & \\
\hline & & & & Favorecido & 1,00 & Sim & 1 & \\
\hline & & & & Empenho de referência & 1,00 & Sim & 1 & \\
\hline 6 & & & \multicolumn{2}{|c|}{$\begin{array}{l}\text { Possibilita a consulta de empenhos ou pagamentos } \\
\text { por favorecido }\end{array}$} & 3,00 & Sim & 3 & \\
\hline 7 & & & \multicolumn{2}{|c|}{$\begin{array}{l}\text { Permite gerar relatório da consulta de empenhos ou } \\
\text { de pagamentos em formato aberto }\end{array}$} & 1,00 & Sim & 1 & \\
\hline \multirow{4}{*}{8} & \multirow{21}{*}{\multicolumn{2}{|c|}{ 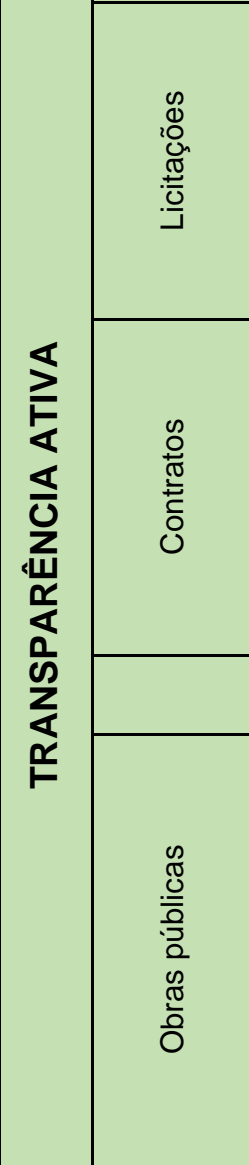 }} & \multirow{4}{*}{ Processos licitatórios } & Número/Ano do Edital & 0,75 & Sim & 0,75 & \\
\hline & & & & Modalidade & 0,75 & Sim & 0,75 & \\
\hline & & & & Objeto & 0,75 & Sim & 0,75 & \\
\hline & & & & Situação/Status & 0,75 & Sim & 0,75 & $9,00 \%$ \\
\hline 9 & & & Disponibiliza o conteú & do integral dos editais & 3,00 & Sim & 3 & \\
\hline 10 & & & $\begin{array}{l}\text { Possibilita a consulta } \\
\text { ocorridas }\end{array}$ & os resultados das licitações & 3,00 & Não & 0 & \\
\hline & & & & Objeto & 0,80 & Não & 0 & \\
\hline & & & & Valor & 0,80 & Não & 0 & \\
\hline 11 & & & Radra dos sontratos & Favorecido & 0,80 & Não & 0 & \\
\hline 11 & & & Lauos uos comiliatus & Número/Ano do contrato & 0,80 & Não & 0 & $4,80 \%$ \\
\hline & & & & \begin{tabular}{|l|} 
Vigência \\
\end{tabular} & 0,80 & Não & 0 & \\
\hline & & & & Licitação de origem & 0,50 & Não & 0 & \\
\hline 12 & & & Disponibiliza o conteú & lo integral dos contratos & 0,30 & Não & 0 & \\
\hline 13 & & & $\begin{array}{l}\text { Permite gerar relatóric } \\
\text { de contratos em forma }\end{array}$ & $\begin{array}{l}\text { da consulta de licitações ou } \\
\text { to aberto }\end{array}$ & 1,00 & Não & 0 & $1,00 \%$ \\
\hline & & & & Objeto & 0,40 & Não & 0 & \\
\hline & & & & \begin{tabular}{|l|} 
Valor total \\
\end{tabular} & 0,40 & Não & 0 & \\
\hline & & & & Empresa contratada & 0,40 & Não & 0 & \\
\hline & & & & Data de início & 0,40 & Não & 0 & \\
\hline 14 & & & $\begin{array}{l}\text { Dados para } \\
\text { acompanhamento }\end{array}$ & \begin{tabular}{|l|} 
Data prevista para término ou \\
prazo de execução
\end{tabular} & 0,40 & Não & 0 & $2,60 \%$ \\
\hline & & & & $\begin{array}{l}\text { Valor total já pago ou } \\
\text { percentual de execução } \\
\text { financeira }\end{array}$ & 0,30 & Não & 0 & \\
\hline & & & & Situação atual da obra & 0,30 & Não & 0 & \\
\hline & & & & Nome & 1,00 & Sim & 1 & \\
\hline 15 & & Servidores & Públicos & Cargo/Função & 1,00 & Sim & 1 & $4,00 \%$ \\
\hline & & & & Remuneração & 2,00 & Sim & 2 & \\
\hline
\end{tabular}




\begin{tabular}{|c|c|c|c|c|c|c|c|c|}
\hline Ordem & \multicolumn{2}{|c|}{ Detalhamento } & \multicolumn{2}{|c|}{ Temas/Parâmetros } & $\begin{array}{l}\text { Pontuação } \\
\text { máxima }\end{array}$ & $\begin{array}{l}\text { Informação } \\
\text { localizada? } \\
\text { (Sim ou Não) }\end{array}$ & Pontuação & $\%$ \\
\hline \multirow{5}{*}{16} & & \multirow{5}{*}{\multicolumn{2}{|c|}{ Despesas com diárias }} & Nome do beneficiário & 0,80 & Sim & 0,8 & \multirow{5}{*}{$4,00 \%$} \\
\hline & & & & Valores recebidos & 0,80 & Sim & 0,8 & \\
\hline & & & & Período da viagem & 0,80 & Sim & 0,8 & \\
\hline & & & & Destino da viagem & 0,80 & Sim & 0,8 & \\
\hline & & & & Motivo da viagem & 0,80 & Sim & 0,8 & \\
\hline 17 & & \multicolumn{2}{|c|}{$\begin{array}{l}\text { Regulamentação da Lei de } \\
\text { Acesso à Informação }\end{array}$} & $\begin{array}{l}\text { Divulgação do normativo } \\
\text { local que regulamenta a LAI } \\
\text { em local de fácil acesso. }\end{array}$ & 2,50 & Não & 0 & $2,50 \%$ \\
\hline \multirow{3}{*}{18} & & \multirow{3}{*}{ 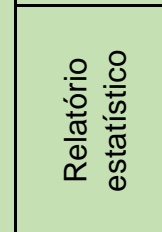 } & \multirow{3}{*}{$\begin{array}{l}\text { Divulgação de } \\
\text { relatório de } \\
\text { atendimentos }\end{array}$} & $\begin{array}{l}\text { Quantidade de pedidos } \\
\text { recebidos }\end{array}$ & 1,00 & Não & 0 & \multirow{3}{*}{$2,00 \%$} \\
\hline & & & & $\begin{array}{l}\text { Quantidade e/ou percentual } \\
\text { de pedidos atendidos }\end{array}$ & 1,00 & Não & 0 & \\
\hline & & & & $\begin{array}{l}\text { Quantidade e/ou percentual } \\
\text { de pedidos indeferidos }\end{array}$ & $x$ & Não & 0 & \\
\hline 19 & & \multicolumn{2}{|c|}{ Bases de dados abertos } & $\begin{array}{l}\text { Publica na internete relação } \\
\text { das bases de dados abertos } \\
\text { do município ou do estado }\end{array}$ & 0,50 & Não & 0 & $0,50 \%$ \\
\hline \multicolumn{8}{|c|}{ TRANSPARÊNCIA ATIVA } & $50,00 \%$ \\
\hline \multirow{5}{*}{1} & \multirow{20}{*}{ 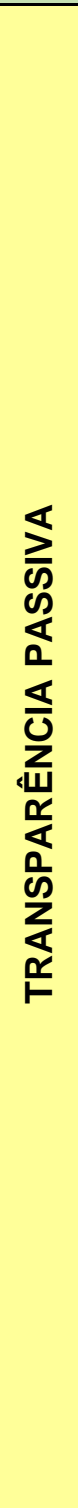 } & \multirow{5}{*}{ 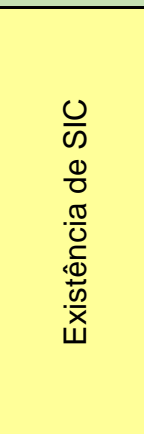 } & \multirow{5}{*}{\begin{tabular}{|l} 
Indica o \\
funcionamento de um \\
SIC físico, isto é, com \\
a possibilidade de \\
entrega de um pedido \\
de informação de \\
Existência de \\
alternativa de envio de \\
pedidos de acesso à \\
informação de forma \\
eletrônica \\
\end{tabular}} & Endereço & 1,00 & Não & 0 & \multirow{3}{*}{$3,00 \%$} \\
\hline & & & & Telefone & 1,00 & Não & 0 & \\
\hline & & & & Horário de atendimento & 1,00 & Não & 0 & \\
\hline & & & & Sistema ou formulário & 6,00 & Sim & 6 & \multirow{2}{*}{$6,00 \%$} \\
\hline & & & & E-mail & 4,00 & Não & 0 & \\
\hline 2 & & & $\begin{array}{l}\text { Não são feitas exigênci } \\
\text { impossibilitem o acessc }\end{array}$ & $\begin{array}{l}\text { ias que dificultem ou } \\
\text { o à informação }\end{array}$ & 4,00 & Não & 0 & $4,00 \%$ \\
\hline \multirow{2}{*}{3} & & & $\begin{array}{l}\text { Permite o } \\
\text { acompanhamento }\end{array}$ & Data de registro do pedido & 2,00 & Sim & 2 & \multirow{2}{*}{$4,00 \%$} \\
\hline & & & \begin{tabular}{|l} 
posterior da \\
solicitação
\end{tabular} & Situação do pedido & 2,00 & Sim & 2 & \\
\hline \multirow{3}{*}{4} & & & & Resposta ao Pedido 1 & 0,50 & Sim & 0,5 & \multirow{3}{*}{$1,50 \%$} \\
\hline & & & hedidos de informacão & Resposta ao Pedido 2 & 0,50 & Sim & 0,5 & \\
\hline & & & & Resposta ao Pedido 3 & 0,50 & Sim & 0,5 & \\
\hline \multirow{3}{*}{5} & & $\frac{0}{\omega}$ & & $\begin{array}{l}\text { Resposta no prazo para o } \\
\text { Pedido } 1\end{array}$ & 3,00 & Sim & 3 & \multirow{3}{*}{$9,00 \%$} \\
\hline & & 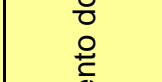 & para resposta das & \begin{tabular}{|l|} 
Resposta no prazo para o \\
Pedido 2
\end{tabular} & 3,00 & Não & 0 & \\
\hline & & $\sum_{\stackrel{\bar{E}}{\varpi}}^{\bar{E}}$ & & $\begin{array}{l}\text { Resposta no prazo para o } \\
\text { Pedido } 3\end{array}$ & 3,00 & Sim & 3 & \\
\hline \multirow{3}{*}{6} & & $\begin{array}{l}\frac{\overline{0}}{0} \\
\frac{5}{5}\end{array}$ & & $\begin{array}{l}\text { Resposta em conformidade } \\
\text { para o Pedido } 1\end{array}$ & 7,00 & Sim & 7 & \multirow{3}{*}{$21,00 \%$} \\
\hline & & & respondendo o que se & $\begin{array}{l}\text { Resposta em conformidade } \\
\text { para o Pedido } 2\end{array}$ & 7,00 & Sim & 7 & \\
\hline & & & & $\begin{array}{l}\begin{array}{l}\text { Resposta em conformidade } \\
\text { para o Pedido } 3\end{array} \\
\end{array}$ & 7,00 & Sim & 7 & \\
\hline \multirow{3}{*}{7} & & & Comunica sobre & $\begin{array}{l}\text { Comunicação existente na } \\
\text { resposta ao Pedido } 1\end{array}$ & 0,50 & Sim & 0,5 & \multirow{3}{*}{$1,50 \%$} \\
\hline & & & possibilidade de & $\begin{array}{l}\text { Comunicação existente na } \\
\text { resposta ao Pedido } 2\end{array}$ & 0,50 & Sim & 0,5 & \\
\hline & & & & \begin{tabular}{|l|} 
Comunicação existente na \\
resposta ao Pedido 3
\end{tabular} & 0,50 & Sim & 0,5 & \\
\hline & & & TRANSP & ARÊNCIA PASSIVA & & & 40 & $50,00 \%$ \\
\hline & & & TOTAL & & 100 & & 68,2 & $100,00 \%$ \\
\hline
\end{tabular}




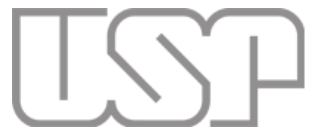

\section{Acesso Público}

Enviar Solicitação

Acesso Restrito

Entrar

Esqueci a Senha

Primeiro Acesso

\section{Universidade de São Paulo}

Brasil

Mensagem

Código: 188462

Assunto: Serviço de Infomação ao Cidadão - USP - Outros

Solicitante: Michel Lutaif - (michel.lutaif@usp.br) em 18/08/2019 11:37

CPF: $350.232 .218-06$

Situação: Respondido ao Usuário

Cadastro: 18/08/2019 11:37

Limite de

Resposa: 19/09/2019 11:04(-)

Mensagem: Olá,

Gostaria de ter acesso aos dados relativos à transparência da universidade, tanto em relação ao SIC-USP quanto em relação ao SIC.SP, no período em que a universidade fazia parte deste, para realização de pesquisa de pós-graduação pela FD.

Poderiam ser enviados dados relativos a:

1) Quantidade de pedidos de informação realizados;

2) Categoria na qual se enquadram os solicitantes (alunos, professores, servidores, público

externo,...);

3) Prazo médio das respostas;

4) Quantidade de pedidos atendidos e quantidade de negados (ou porcentagem);

5) Motivos da negativa dos pedidos (quantos por conter informações pessoais, quantos por conterem hipóteses legais de sigilo e quantos classificados);

6) Quantidade de pedidos não respondidos na instância inicial;

7) Quantidade de recursos apresentados;

8) Quantidade de recursos deferidos e indeferidos em cada instância;

9) Se houver, as principais temáticas dos pedidos realizados (dados demográficos da universidade, informações contábeis e financeiras, acesso a documentos, etc.)

10) Órgão responsável pela fiscalização da LAI na USP.

11) Responsável pela alimentação do Portal da Transparência da USP e seu contato.

Não desejo ter acesso ao conteúdo de nenhum dos pedidos, apenas a esses dados numéricos.

Caso não exista algum dos dados com os filtros requeridos ou não seja possível seu envio, basta apenas apontar ou entrar em contato para fornecer acesso alternativo.

Se possível, informar se o dado enviado diz respeito apenas aos pedidos realizados no SIC-USP, no SIC.SP ou se é relativo aos dois sistemas juntos.

Muito obrigado!

Reconsiderar Mensagem

\section{Motivo}

Anexo

Escolher arquivo Nenhum arquivo selecionado 
1 registro(s) encontrado(s)!

\section{[2 - Respondido ao Usuário] em 09/09/2019 11:22}

Prezado Michel,

Estamos encaminhando link para acesso e download dos relatórios estatísticos, simplificados e relativos a classificação dos requerentes, relativos aos atendimentos realizados via Sistemas de Informação ao Cidadão da USP e/ou via SIC-SP.

Esclarecemos que o Sistema de Informação ao Cidadão da Universidade de São Paulo (SIC-USP), foi disponibilizado em meados de junho/julho de 2015 e ainda não dispõe de funções que ofereça a consolidação dos dados que atenda a todas as suas solicitação.

Informamos ainda, que o relatórios de atendimentos contendo as solicitações e respostas dadas estão em tratamento para anonimização dos dados pessoais e sensíveis e tão logo esteja pronto, será disponibilizado junto ao Portal da Transparência (https://www5.usp.br/transparencia/).

Atendimentos realizados via SIC-SP (2012-2019)

Respondido para o email michel.lutaif@usp.br
Rel. Simplificado - https://drive.google.com/open? id=10_hUoqW_nke3eQVKMI5fYvLI4Fyz7I3F

Rel. Estatístico - https://drive.google.com/open? id=1BVuHPhseWd6nIIukmmqN5ynPTUJZnpTo

Rel. Estatístico Recursos - https://drive.google.com/open?

id=1FPT6sBVDhJExAKZYgPO3uOVsxMQUJjX4

Rel. Perfil Requerentes - https://drive.google.com/open?

id=18ezBCPkIQR2GR3nqwv8L3ErANrkoa8MV

Atendimentos realizados via SIC-USP (2015-2019-1)

Rel. Simplificado - https://drive.google.com/open?

id=1gIpxeKy2xpoUr4M_7Y9XX2jRqt1Bp4IG

Rel. Estatístico - https://drive.google.com/open?

id=155vekAM7_FI0xfc61IDjkXKc3tR7wYIU

Para qualquer outra informação relativa à Universidade de São Paulo prevista na Lei 12.527/2011, por favor, faça novo pedido em formulário digital disponível em www.transparencia.usp.br

Atenciosamente,

SIC - Serviço de Informação ao Cidadão

Universidade de São Paulo 


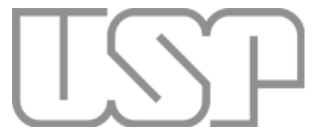

\section{Acesso Público}

Enviar Solicitação

Acesso Restrito

Entrar

Esqueci a Senha

Primeiro Acesso
Universidade de São Paulo

Brasil

Mensagem

Código: 189980

Assunto: Serviço de Infomação ao Cidadão - USP - Outros

Solicitante: Michel Lutaif - (michel.lutaif@usp.br) em 14/09/2019 13:09

CPF: $350.232 .218-06$

Situação: Respondido ao Usuário

Cadastro: 14/09/2019 13:09

Limite de

Resposa: 17/10/2019 11:42(-)

Mensagem: Boa tarde.

Para realização de pesquisa de pós-graduação no âmbito da FD, gostaria de fazer alguns questionamentos em relação às auditorias realizadas na universidade:

1- Já houve em algum momento realização de auditoria externa, por empresa contratada pela USP?

2- Existe alguma regulamentação ou normativa para os procedimentos de realização das auditorias?

3- Em relação às auditorias realizadas internamente, estas são conduzidas apenas pelo Serviço de Auditoria Interna do Departamento de Finanças da Codage?

4- Que tipo de contas ou contratos são auditados pelo DFEAI? As auditorias são feitas por recorte temático ou por valor? Se sim, quais são?

5- $\quad$ As auditorias são realizadas sobre todos os contratos e contas, ou por demanda ou por amostragem?

6- Já foi realizada em algum momento auditoria da folha de pagamentos da USP?

7- É possível enviar a relação de auditorias internas já realizadas pelo DFEAI? Não há necessidade de enviar os relatórios completos das auditorias, mas apenas informações como o que foi feito, em qual ou quais unidades da USP, o que foi auditado, data e conclusão.

8- $\quad$ Existe algum dado que demonstre o quanto de recursos públicos a universidade deixou de gastar/economizou em decorrência da correção realizada a partir de uma irregularidade detectada pela atividade de auditoria?

Muito obrigado e fico à disposição para esclarecer alguma dúvida em relação aos questionamentos.

\section{Motivo}

\section{Anexo}

Escolher arquivo Nenhum arquivo selecionado

Enviar

\section{Andamentos}

\section{3 registro(s) encontrado(s)!}

\section{[4 - Respondido ao Usuário] em 21/10/2019 13:18}


Em resposta ao seu pedido de reconsideração, o Departamento de Finanças (DF) da Universidade de São Paulo, encaminha planilha contendo os dados solicitados.

Para qualquer outra informação relativa à Universidade de São Paulo prevista na Lei $12.527 / 2011$, por favor, faça novo pedido em formulário digital disponível em www.transparencia.usp.br

Atenciosamente,

SIC - Serviço de Informação ao Cidadão

Universidade de São Paulo

\section{[3 - Cadastrado] em 13/10/2019 01:21}

Mensagem reconsiderada por solicitação do remetente
Prezados, agradeço pelas respostas enviadas, que auxiliarão muito na pesquisa realizada.

Contudo, devo recorrer da resposta ao item no 7 . Foi perguntado se seria possível o envio da relação ou lista das auditorias internas já realizadas pelo DFEAI na USP, contendo alguns dados básicos como unidade, objeto da auditoria, data e conclusão.

A resposta limitou-se a informar que as auditorias possuem cunho interno, mas não justificou os motivos pelos quais não seria possível o envio (sigilo decorrente de lei, informações pessoais ou classificadas como sigilosas).

Reforço, então, o pedido inicial, requerendo o envio se não houver alguma justificativa legal para a restrição ao seu acesso.

Muito obrigado!

\section{[2 - Respondido ao Usuário] em 11/10/2019 09:31}

Respondido para o email michel.lutaif@usp.br
Prezado Michel,

O Departamento de Finanças (DF) da Universidade de São Paulo, encaminha as respostas e esclarecimentos aos seus questionamentos:

1- Já houve em algum momento realização de auditoria externa, por empresa contratada pela USP?

Resp.: Não. As contas da Universidade são auditadas pelo Tribunal de Contas do Estado

2- Existe alguma regulamentação ou normativa para os procedimentos de realização das auditorias?

Resp.: Os trabalhos são conduzidos em observância à legislação e normas internas da USP aplicáveis à execução orçamentária

3- Em relação às auditorias realizadas internamente, estas são conduzidas apenas pelo Serviço de Auditoria Interna do Departamento de Finanças da Codage?

Resp.: O DFEAI realiza auditorias com foco na análise da execução orçamentária das Unidades/Órgãos da USP. Por sua vez, as Unidades e Órgãos contam com profissionais que podem realizar auditagem dos procedimentos internos.

4- Que tipo de contas ou contratos são auditados pelo DFEAI? As auditorias são feitas por recorte temático ou por valor? Se sim, quais são?.

Resp.: Os trabalhos de auditorias focam a execução orçamentária, que pode envolver compras, contratações, adiantamentos, recolhimentos, etc.

5- As auditorias são realizadas sobre todos os contratos e contas, ou por demanda ou por amostragem?

Resp.: Por demanda ou amostragem

6- Já foi realizada em algum momento auditoria da folha de pagamentos da USP?

Resp.: Sim.

7- É possível enviar a relação de auditorias internas já realizadas pelo DFEAI? Não há necessidade de enviar os relatórios completos das auditorias, mas apenas informações como o que foi feito, em qual ou quais unidades da USP, o que foi auditado, data e conclusão.

Resp.: As auditorias realizadas pelo DFEAI são de cunho interno e tem por finalidade promover melhorias na execução orçamentária e consequentemente na gestão dos recursos públicos.

8- Existe algum dado que demonstre o quanto de recursos públicos a universidade deixou de gastar/economizou em decorrência da correção realizada a partir de uma irregularidade detectada pela atividade de auditoria?"

Resp.: Não há dados com estas informações.

Para qualquer outra informação relativa à Universidade de São Paulo prevista na Lei $12.527 / 2011$, por favor, faça novo pedido em formulário digital disponível em www.transparencia.usp.br

Atenciosamente, 
SIC - Serviço de Informação ao Cidadão

Universidade de São Paulo 


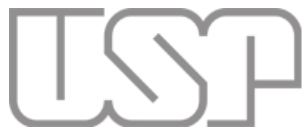

\section{Acesso Público}

Enviar Solicitação

Acesso Restrito

Entrar

Esqueci a Senha

Primeiro Acesso

\section{Universidade de São Paulo}

Brasil

Mensagem

Código: 191300

Assunto: Serviço de Infomação ao Cidadão - USP - Outros

Solicitante: Michel Lutaif - (michel.lutaif@usp.br) em 13/10/2019 01:15

CPF: $350.232 .218-06$

Situação: Respondido ao Usuário

Cadastro: 13/10/2019 01:15

Limite de

Resposa: $15 / 11 / 201914: 22(-)$

Mensagem: Prezados, para fins de pesquisa de pós-graduação na Faculdade de Direito, gostaria de obter respostas para as seguintes perguntas:

1) É possível encontrar informações sobre os contratos firmados pela universidade em transparência ativa (como objeto, valor, dados do contratado e licitação de origem), ou seu acesso se dá apenas por transparência passiva?

2) É possível encontrar informações sobre obras públicas realizadas pela universidade em transparência ativa (como objeto da obra, valor, contratado, situação da obra) ou o acesso a este tipo de dado se dá apenas por transparência passiva?

Se os dados estiverem disponíveis em transparência ativa, favor indicar o endereço eletrônico em que posso encontrá-los.

Muito obrigado!

Reconsiderar Mensagem

\section{Motivo}

\section{Anexo}

Escolher arquivo Nenhum arquivo selecionado

\section{Enviar}

\section{Andamentos}

\section{1 registro(s) encontrado(s)!}

\section{[2 - Respondido ao Usuário] em 08/11/2019 14:00}

Respondido para o email michel.lutaif@usp.br
Caro Michel,

O Universidade de São Paulo, dá os seguintes esclarecimentos aos seus questionamentos:

1) É possível encontrar informações sobre os contratos firmados pela universidade em transparência ativa (como objeto, valor, dados do contratado e licitação de origem), ou seu acesso se dá apenas por transparência passiva?

Resposta: Não, somente através da transparência passiva. Cada unidade/órgão é responsável pelo seus processos e contratos firmados.

2) É possível encontrar informações sobre obras públicas realizadas pela universidade em transparência ativa (como objeto da obra, valor, contratado, 
situação da obra) ou o acesso a este tipo de dado se dá apenas por transparência passiva?

Resposta: Não, somente através da transparência passiva. Quando se trata de obras internas (unidades/órgãos), o processo contendo os dados ficam sob a responsabilidade da unidade sob a fiscalização da Superintendência do Espaço Físico (SEF). Se a obra for no espaço comum, o processo é de responsabilidade da SEF.

Atenciosamente,

SIC - Serviço de Informação ao Cidadão

Universidade de São Paulo

Caso não fique satisfeito com a resposta ou com o serviço, recomendamos os procedimentos abaixo indicados:

1) NOVA SOLICITAÇÃO - Formule uma nova solicitação de informação ao SIC-USP, esclarecendo melhor o solicitado. www.transparencia.usp.br

2) CONTATE A OUVIDORIA GERAL DA USP - Formalize uma reclamação e/ou sugestão relativo ao atendimento. https://www5.usp.br/ouvidoria/ouvidoria-geralda-usp-registre-sua-reclamacao/

3) Entre com um recurso (Reconsideração da Resposta): em MOTIVOS, faça as suas considerações referentes à resposta dada e/ou solicite as informações complementares que deseja acessar.

O PRAZO para entrar com recurso é de 40 (quarenta) dias, a contar da data do protocolo da solicitação. 